\title{
Specific Hypersensitive Response-Associated Recognition of New Apoplastic Effectors from Cladosporium fulvum in Wild Tomato
}

\author{
Carl H. Mesarich, ${ }^{1,2,3, \dagger}$ Bilal Ökmen, ${ }^{1}$ Hanna Rovenich, ${ }^{1}$ Scott A. Griffiths, ${ }^{1}$ Changchun Wang, ${ }^{1,4}$ \\ Mansoor Karimi Jashni, ${ }^{1,5}$ Aleksandar Mihajlovski, ${ }^{1}$ Jérôme Collemare, ${ }^{1}$ Lukas Hunziker, ${ }^{3,6}$ \\ Cecilia H. Deng, ${ }^{7}$ Ate van der Burgt, ${ }^{1}$ Henriek G. Beenen, ${ }^{1}$ Matthew D. Templeton, ${ }^{3,7}$ \\ Rosie E. Bradshaw, ${ }^{3,6}$ and Pierre J. G. M. de Wit ${ }^{1,8}$
}

${ }^{1}$ Laboratory of Phytopathology, Wageningen University, Droevendaalsesteeg 1, 6708 PB Wageningen, The Netherlands;
${ }^{2}$ Laboratory of Molecular Plant Pathology, Institute of Agriculture \& Environment, Massey University, Private Bag 11222,
Palmerston North 4442, New Zealand; ${ }^{3}$ Bio-Protection Research Centre, New Zealand; ${ }^{4}$ College of Chemistry and Life
Sciences, Zhejiang Normal University, Jinhua, Zhejiang 321004 , People's Republic of China; ${ }^{5}$ Department of Plant Pathology,
Iranian Research Institute of Plant Protection, Agricultural Research, Education and Extension Organization, P.O. Box 19395-
1454, Tehran, Iran; ${ }^{6}$ Institute of Fundamental Sciences, Massey University, Private Bag 11222, Palmerston North 4442, New
Zealand; ${ }^{7}$ Breeding \& Genomics/Bioprotection Portfolio, the New Zealand Institute for Plant \& Food Research Limited, Mount
Albert Research Centre, Auckland 1025, New Zealand; and ${ }^{8}$ Centre for BioSystems Genomics, P.O. Box 98, 6700 AB

Wageningen, The Netherlands

Accepted 11 September 2017.

Tomato leaf mold disease is caused by the biotrophic fungus Cladosporium fulvum. During infection, C. fulvum produces extracellular small secreted protein (SSP) effectors that function to promote colonization of the leaf apoplast. Resistance to the disease is governed by $\mathrm{Cf}$ immune receptor genes that encode receptor-like proteins (RLPs). These RLPs recognize specific SSP effectors to initiate a hypersensitive response (HR) that renders the pathogen avirulent. $C$. fulvum strains capable of overcoming one or more of all cloned $\mathrm{Cf}$ genes have now emerged. To combat these strains, new $\mathrm{Cf}$ genes are required. An effectoromics approach was employed to identify wild tomato accessions carrying new Cf genes. Proteomics and transcriptome sequencing were first used to identify 70 apoplastic in planta-induced $C$. fulvum SSPs. Based on sequence homology, 61 of these SSPs were novel or lacked known functional

Nucleotide sequence data is available in the GenBank database under the following accession numbers: Ecp6, KX943112; Ecp7, KX943113; Ecp8, KX943038; Ecp9-1, KX943041; Ecp9-2, KX943114; Ecp9-3, KX943115; Ecp9-4, KX943116; Ecp9-5, KX943117; Ecp9-6, KX943118; Ecp9-7, KX943119; Ecp9-8, KX943120; Ecp9-9, KX943081; Ecp10-1, KX943046; Ecp10-2, KX943063; Ecp10-3, KX943121; Ecp11-1, KX943050; Ecp12, KX943058; Ecp13, KX943065; Ecp14-1, KX943087; Ecp14-2, KX943122; Ecp15, KX943091; Ecp16, KX943080; Ecp17, KX943051; Ecp18, KX943035; Ecp19-1, KX943036; Ecp19-2, KX943048; Ecp20-1, KX943037; Ecp20-2, KX943057; Ecp20-3, KX943096; Ecp21-1, KX943039; Ecp22, KX943040; Ecp23, KX943044; Ecp24-1, KX943045; Ecp24-2, KX943094; Ecp25, KX943047; Ecp26, KX943052; Ecp27, KX943054; Ecp28-1, KX943056; Ecp28-2, KX943088; Ecp28-3, KX943090; Ecp29, KX943103; Есp30, KX943076; Ecp31, KX943059; Ecp32-1, KX943062; Ecp32-2, KX943101; Ecp33, KX943066; Ecp34, KX943067; Ecp35, KX943068; Ecp36-1, KX943069; Еср37, KX943072; Ecp38, KX943073; Есp39, KX943074; Ecp40, KX943079; Ecp41, KX943082; Ecp42, KX943083; Ecp43-1, KX943089; Ecp44, KX943092; Ecp45, KX943093; Ecp46, KX943095; Ecp47, KX943097; Ecp48, KX943098; Ecp49-1, KX943099; Ecp50-1, KX943100; Ecp51, KX943102; Ecp52, KX943104; Ecp53-1, KX943105; Ecp54-1, KX943107; Ecp55, KX943108; Ecp56, KX943110; Ecp57-1,

@ 2018 The American Phytopathological Society domains. Seven, however, had predicted structural homology to antimicrobial proteins, suggesting a possible role in mediating antagonistic microbe-microbe interactions in planta. Wild tomato accessions were then screened for $\mathrm{HR}$-associated recognition of 41 SSPs, using the Potato virus $X$-based transient expression system. Nine SSPs were recognized by one or more accessions, suggesting that these plants carry new $\mathrm{Cf}$ genes available for incorporation into cultivated tomato.

Leaf mold disease of tomato (Solanum lycopersicum) is caused by the biotrophic Dothideomycete fungal pathogen Cladosporium fulvum (syn. Passalora fulva and Fulvia fulva) (Thomma et al. 2005). The fungus likely originated in South America, the center of origin for tomato (Jenkins 1948), with

KX943153; Ecp58-1, KX943126; Ecp59-1, KX943193; Ecp60-1, KX943150; CfPhiA-1, KX943043; CfPhiA-2, KX943085.

Current address for Bilal Ökmen and Hanna Rovenich: Botanical Institute and Cluster of Excellence on Plant Sciences, University of Cologne, 50674 Cologne, Germany.

Current address for Aleksandar Mihajlovski: Food and Agriculture Organization of the United Nations, Viale delle Terme di Caracalla, 00153 Rome, Italy.

Current address for Scott A. Griffiths and Jérôme Collemare: Westerdijk Fungal Biodiversity Institute, Uppsalalaan 8, 3584 CT Utrecht, The Netherlands.

Current address for Ate van der Burgt and Henriek G. Beenen: DuPont Industrial Biosciences Wageningen, Nieuwe Kanaal 7-S, 6709 PA Wageningen, The Netherlands.

${ }^{\dagger}$ Corresponding author: Carl H. Mesarich;
E-mail: c.mesarich@massey.ac.nz

*The $\boldsymbol{e}$-Xtra logo stands for "electronic extra" and indicates that 17 supplementary figures, six supplementary tables, and two supplementary text files are published online. 
the first disease outbreak reported in South Carolina during the late 1800s (Cooke 1883). C. fulvum now occurs worldwide but is primarily a problem in greenhouse and high-tunnel environments, in which tomato plants are exposed to both moderate temperatures and high relative humidity. Disease symptoms are typified by pale green to yellow spots on the adaxial leaf surface as well as white to olive-green patches of mold on the abaxial leaf surface that turn brown upon sporulation. In the late stages of disease development, this sporulation is often associated with leaf wilting and partial defoliation, which, in severe infections, can cause death of the plant (Thomma et al. 2005).

During infection (i.e., in a compatible interaction), C. fulvum exclusively colonizes the tomato leaf apoplast, in which it grows in close contact with surrounding mesophyll cells (Thomma et al. 2005). This colonization is promoted through a collection of virulence factors, termed effector proteins, which the fungus secretes into the apoplastic environment (Laugé et al. 1997). To date, 13 C. fulvum effectors have been identified and the genes encoding these proteins have been cloned (Bolton et al. 2008; Joosten et al. 1994; Laugé et al. 2000; Luderer et al. 2002a; Mesarich et al. 2014; Ökmen et al. 2013; Stergiopoulos et al. 2012; Van den Ackerveken et al. 1993; van Kan et al. 1991; Westerink et al. 2004). The majority (11 of 13) are small secreted proteins (SSPs) of less than 300 amino-acid residues in length with i) an amino $(\mathrm{N})$-terminal signal peptide for secretion into the tomato leaf apoplast and ii) four or more cysteine (Cys) residues following their signal peptide cleavage site. An intrinsic virulence function has been determined for three of the 11 SSP effectors. The first of these, Avr2, which lacks a known functional domain, targets and inhibits at least four Cys proteases of tomato (Rcr3, Pip1, aleurain, and TDI-65) to prevent the degradation of $C$. fulvum proteins (Krüger et al. 2002; Rooney et al. 2005; Shabab et al. 2008; van Esse et al. 2008). The second, Avr4, possesses a carbohydratebinding module family 14 domain (CBM_14; PF01607) that binds chitin present in the cell wall of $C$. fulvum to protect against hydrolysis by basic plant chitinases (van den Burg et al. 2004, 2006; van Esse et al. 2007). The third, Ecp6, possesses three lysin motif domains (LysM, PF01476) that function to perturb chitin-triggered immunity (Bolton et al. 2008; de Jonge et al. 2010; Sánchez-Vallet et al. 2013). More specifically, two of the LysM domains cooperate to sequester chitin fragments released from the cell wall of invading hyphae and, in doing so, outcompete host chitin immune receptors for the binding of chitin fragments (Sánchez-Vallet et al. 2013). The third LysM domain has been proposed to perturb chitintriggered immunity through interference with the host chitin immune receptor complex (Sánchez-Vallet et al. 2013).

Despite their roles in virulence, the same effectors can also be an Achilles heel for C. fulvum. In certain accessions of tomato, specific effectors or their modulated targets can be directly or indirectly recognized, respectively, by corresponding $\mathrm{Cf}$ immune receptor proteins, to trigger immune responses that render the pathogen avirulent (Cook et al. 2015; de Wit et al. 2009; Wulff et al. 2009b). In such incompatible interactions, the main output of the immune system is the hypersensitive response (HR), a localized form of cell death that arrests growth of the pathogen at the infection site (Heath 2000). So far, 10 of the 11 C. fulvum SSP effectors, specifically Avr2, Avr4, Avr4E, Avr5, Avr9, Ecp1, Ecp2-1, Ecp4, Ecp5, and Ecp6, are known to be recognized as avirulence (Avr) determinants by the corresponding $\mathrm{Cf}$ immune receptors Cf-2.1/Cf-2.2, Cf-4, Cf-4E, Cf-5, Cf-9, Cf- Ecp1, Cf-Ecp2-1, Cf-Ecp4, Cf-Ecp5, and Cf-Ecp6, respectively (de Wit et al. 2009; Thomma et al. 2011). All Cf immune receptor genes cloned to date encode receptor-like protein (RLP) cell-surface receptors that possess extracytoplasmic leucine-rich repeats (eLRRs), a transmembrane domain, and a short cytoplasmic tail (Dixon et al. 1996, 1998; Jones et al. 1994; Panter et al. 2002; Takken et al. 1999; Thomas et al. 1997).
Several studies suggest that the eLRRs are responsible for the direct or indirect recognition of $C$. fulvum effector proteins in the tomato leaf apoplast (Seear and Dixon 2003; Van der Hoorn et al. 2001a; Wulff et al. 2001, 2009a).

It was determined early on that wild Solanum species and landraces are a rich source of resistance against $C$. fulvum. Indeed, all cloned $\mathrm{Cf}$ immune receptor genes are derived from wild $\mathrm{So}$ lanum species or landraces, with $C f-2.1 / C f-2.2, C f-9 / C f-9 D C$, and $C f-9 B$ from Solanum pimpinellifolium (Dixon et al. 1996; Jones et al. 1994; Panter et al. 2002; Van der Hoorn et al. 2001b), $C f-4$ and $C f-4 E$ from Solanum habrochaites (Takken et al. 1999; Thomas et al. 1997), and Cf-5 from the landrace Solanum lycopersicum var. cerasiforme (Dixon et al. 1998). Based on this knowledge, $\mathrm{Cf}$ immune receptor genes were introgressed from wild Solanum species and landraces into cultivated tomato by breeders over several decades (Kerr and Bailey 1964). While largely effective, intensive year-round cultivation of these plants has led to the emergence of natural $C$. fulvum strains capable of overcoming one or more of all cloned $\mathrm{Cf}$ immune receptor genes (Hubbeling 1978; Iida et al. 2015; Laterrot 1986; Li et al. 2015). Several types of sequence modification have been shown to occur in $A v r$ effector genes that permit the evasion of $\mathrm{Cf}$ immune receptor gene-mediated resistance by $C$. fulvum. These are i) gene deletion, ii) the insertion of a transposon-like element (gene disruption), iii) single nucleotide polymorphisms that result in nonsynonymous amino-acid substitutions, and iv) nucleotide insertions or deletions (indels) that result in frameshift mutations (Stergiopoulos et al. 2007). To combat strains capable of overcoming existing resistance specificities, new $\mathrm{Cf}$ immune receptor genes need to be identified for incorporation into cultivated tomato.

Laugé et al. (2000) hypothesized that "any stable, extracellular protein produced by a pathogen during colonization is a potential avirulence factor" and, given that all cloned $\mathrm{Cf}$ immune receptor genes encode an RLP, we set out to identify wild tomato accessions carrying new $\mathrm{Cf}$ immune receptor genes corresponding to apoplastic in planta-induced SSPs of $C$. fulvum, using effectoromics. Effectoromics is a powerful high-throughput functional genomics approach that uses effectors or effector candidates to probe plant germplasm collections for corresponding immune receptors (Domazakis et al. 2017; Du and Vleeshouwers 2014; Vleeshouwers and Oliver 2014). Notably, this approach, which is based on the HR-associated recognition of effectors or effector candidates, has already proven to be successful for the identification of wild accessions and breeding lines of Solanum-carrying Cf immune receptor genes corresponding to known effectors of $C$. fulvum. In a pioneering study by Laugé et al. (1998), 21 S. lycopersicum lines originating from early $C$. fulvum-resistance breeding programs were screened for their ability to recognize Ecp2-1, using the Potato virus $X$ (PVX)-based transient expression system (Hammond-Kosack et al. 1995; Takken et al. 2000), as well as by leaf injection with purified Ecp2-1 protein. Four lines, with the same $S$. pimpinellifolium ancestor, recognized Ecp2-1, indicating for the first time that tomato carries an immune receptor gene corresponding to this effector (Cf-Ecp2-1) (Laugé et al. 1998).

In a follow-up study by Laugé et al. (2000), 28 S. lycopersicum breeding lines, many of which also have a $S$. pimpinellifolium ancestor, were screened for their ability to recognize purified Ecp1, Ecp2-1, Ecp3 (amino-acid sequence not yet known), Ecp4, or Ecp5 protein. Four lines recognized Ecp2-1, while two different lines recognized Ecp3 and Ecp5, respectively (Laugé et al. 2000). In the same study, a collection of 40 different $S$. pimpinellifolium accessions were also screened for their ability to recognize the same five effectors as well as Avr4 and Avr9, using the PVX-based transient expression system. Three different accessions recognized Ecp1, Ecp2-1, and Ecp3 (purified protein), respectively, while two recognized Ecp4, three recognized Ecp5, and six recognized Avr9 
(Laugé et al. 2000). Again, this study indicated for the first time that tomato carries immune receptor genes corresponding to Ecp3 (Cf-Ecp3), Ecp4 (Cf-Ecp4), and Ecp5 (Cf-Ecp5) (Laugé et al. 2000). Three known $C$. fulvum effectors have since been shown to be recognized by wild tomato accessions through infiltration of purified protein, specifically Ecp6 in S. lycopersicum (Thomma et al. 2011) as well as Avr4 and Avr9 in S. pimpinellifolium (Kruijt et al. 2005; Van der Hoorn et al. 2001b).

As a starting point for our effectoromics approach, we used proteomics and transcriptome sequencing to identify 70 apoplastic in planta-induced SSPs of $C$. fulvum. This set of 70 is made up of all 11 known SSP effectors of this fungus as well as two phialide proteins and 57 new extracellular proteins. We screened 41 of these SSPs for HR-associated recognition by wild tomato accessions, using the PVX-based transient expression system. A total of nine SSPs were recognized by one or more of 14 wild tomato accessions, suggesting that these plants carry new $\mathrm{Cf}$ immune receptor genes available for incorporation into cultivated tomato.

\section{RESULTS}

Proteomics and transcriptome sequencing identify 70 apoplastic in planta-induced SSPs of $C$. fulvum.

Liquid-chromatography-tandem mass spectrometry (LCMS/MS) was used to identify fungal peptides corresponding to SSPs present in intercellular washing fluid (IWF) samples of compatible $C$. fulvum-tomato (S. lycopersicum cv. Heinz $[\mathrm{H}]-$ $\mathrm{Cf}-0$ ) interactions. Here, SSPs are defined as those proteins of $<300$ amino-acid residues in length with a predicted $\mathrm{N}$-terminal signal peptide but without a predicted glycophosphatidylinositol (GPI) anchor modification site, one or more transmembrane domains, a carboxyl (C)-terminal endoplasmic reticulum (ER) retention/retention-like signal, or sequence homology to enzymes. Using this approach, 297 unique fungal peptides were mapped to 75 SSPs of $C$. fulvum (Table 1; Supplementary Information S1). Based on pre-existing RNA-Seq transcriptome sequencing data from a compatible $C$. fulvum $0 \mathrm{WU}-S$. lycopersicum cv. H-Cf-0 interaction at 4,8 , and 12 days postinoculation (dpi) as well as from C. fulvum 0WU grown in vitro in potato-dextrose broth (PDB) or Gamborg B5 liquid media at 4 dpi (Mesarich et al. 2014), 70 of the 75 apoplastic SSPs (approximately 93.3\%) were deemed to be encoded by in planta-induced genes (Supplementary Table S1).

Among the 70 apoplastic in planta-induced SSPs are all C. fulvum SSP effectors identified in previous studies (Avr2, Avr4, Avr4E, Avr5, Avr9, Ecp1, Ecp2-1, Ecp4, Ecp5, Ecp6, and Ecp7) (Bolton et al. 2008; Joosten et al. 1994; Laugé et al. 2000; Luderer et al. 2002a; Mesarich et al. 2014; Van den Ackerveken et al. 1993; van Kan et al. 1991; Westerink et al. 2004) as well as 32 of 43 (approximately $74.4 \%$ ) C. fulvum candidate effectors recently discovered using a combined bioinformatic and transcriptome sequencing approach (Mesarich et al. 2014). The latter includes CfPhiA-1, a phialide protein previously identified in the IWF sample of a compatible C. fulvum (strain IPO 1979)-tomato (S. lycopersicum cv. Moneymaker [MM]-Cf-0) interaction at $14 \mathrm{dpi}$ (Bolton et al. 2008). Strikingly, 62 of the 70 apoplastic in plantainduced SSPs (approximately 88.6\%) are both Cys-rich ( $\geq 4$ Cys residues) and have an even number of Cys residues (Table 1).

Basic local alignment search tool (BLAST) homology searches against publicly available sequence databases at the National Center for Biotechnology Information (NCBI) and the Joint Genome Institute (JGI) revealed that 14 of the 70 apoplastic in planta-induced SSPs are novel (20\%), while 47 (approximately $67.1 \%$ ) have homology to proteins of unknown function (Table 1). The nine remaining in planta-induced SSPs (approximately $12.9 \%$ ) have known or predicted functional domains or have homology to proteins with characterized biological functions. These are Avr4 (CBM_14 domain, PF01607), Ecp2-1 (Hce2 domain,
PF14856), Ecp6 (three LysM domains, PF01476), CfPhiA-1 and CfPhiA-2 (phialide proteins), Ecp14-1 (class II hydrophobin [Fig. 1]), Ecp44 (GPI-anchored superfamily domain, PF10342), Ecp45 (cerato-platanin protein, PF07249), and Ecp50-1 (hydrophobic surface-binding protein A [HsbA] domain, PF12296) (Table 1). BLAST homology searches and Cys spacing comparisons also revealed that 21 in planta-induced SSPs are related to each other at the amino-acid level. These are Ecp4, Ecp7, and Ecp29 (Cterminal region [CTR] [residues 158 to 266]); Ecp9-1 and Ecp9-9; Ecp10-1 and Ecp10-2; Ecp19-1 and Ecp19-2; Ecp20-1, Ecp20-2, and Ecp20-3; Ecp24-1 and Ecp24-2; Ecp28-1, Ecp28-2, Ecp28-3, and Ecp29 (N-terminal region [NTR] [residues 21 to 113]); Ecp32-1 and Ecp32-2 (IgE-binding proteins); and CfPhiA-1 and CfPhiA-2 (Table 1). Consistent with members of the Ecp2 family (Ecp2-1,Ecp2-2, andEcp2-3) (Stergiopoulos et al. 2012), related extracellular proteins mentioned here have been grouped into families, with each member sequentially numbered using an extension (i.e., -1, -2, and -3). The exceptions are Ecp4 and Ecp7, which were named in previous studies (Bolton et al. 2008; Laugé et al. 2000), and Ecp29, which belongs to both the Ecp4/7 and Ecp28 families.

As 61 of the 70 apoplastic in planta-induced SSPs (approximately $87.1 \%$ ) are novel or have homology to proteins of unknown function, 10 three-dimensional protein structure prediction servers were employed to infer possible structural relationships between these and proteins of characterized tertiary structure and/or function present in the Research Collaboratory for Structural Bioinformatics protein databank (RCSB protein databank). Three SSPs (Ecp20-1, Ecp20-2, and Ecp20-3) were consistently predicted to have structural homology to Alt a 1 (RCSB protein databank numbers $3 \mathrm{VOR}$ and 4AUD), an allergen protein with a $\beta$-barrel fold (Chruszcz et al. 2012) from the broad host-range Dothideomycete fungal plant pathogen and saprophyte Alternaria alternata (Supplementary Table S2). Four SSPs (Ecp4, Ecp7, Ecp29 [CTR], and Ecp30) were consistently predicted to have structural homology to proteins with a $\beta / \gamma$-crystallin fold, including the plant antimicrobial protein MiAMP1 from Macadamia integrifolia (1C01) (McManus et al. 1999) and the yeast killer toxin WmKT from Williopsis mrakii (1WKT) (Antuch et al. 1996). Three other SSPs (Ecp28-1, Ecp28-2, and Ecp28-3) were consistently predicted to have structural homology to one or both the $\alpha$ and $\beta$ subunits of KP6 (1KP6 and 4GVB), a virus-encoded antifungal killer toxin with an $\alpha / \beta$-sandwich fold secreted by the fungal corn smut pathogen Ustilago maydis (Allen et al. 2013a; Li et al. 1999). Notably, the NTR of Ecp29 was found to share sequence homology with Ecp28-1, Ecp28-2, and Ecp28-3, suggesting that it, too, adopts a KP6-like fold. The NTR and CTR of Ecp29 are separated by a putative kexin protease cleavage site (Supplementary Fig. S1A).

Hidden Markov model (HMM) alignments generated between Ecp20-1 and Alt a 1, Ecp4 and MiAMP1, as well as Ecp28-3 and KP6 $\beta$ (i.e., as part of the HHPred server output [Söding et al. 2005]) are shown in Supplementary Figure S2. In addition to conserved elements of the secondary structure, all three alignments revealed conserved Cys residues. For Ecp20-1 and Alt a 1, two conserved Cys residues at positions 50 and 65 (mature proteins), which are also present in Ecp20-2 and Ecp20-3, were identified. In Alt a 1, these Cys residues are known to form an intramolecular disulphide bond (Chruszcz et al. 2012). Inspection of the predicted Ecp20-1 tertiary structure, which was modeled using Alt a 1 as a template in HHpred (MODELER) (Söding et al. 2005; Webb and Sali 2002) and RaptorX (Källberg et al. 2012), suggests that the conserved Cys50/Cys65 pair forms an intramolecular disulphide bond (Supplementary Fig. S3A). Furthermore, the predicted structure suggests that the two remaining Cys residues, Cys 24 and Cys29, which are absent from Alt a 1, may also form an intramolecular disulphide bond, given that they are located in close proximity to each other. This bond, however, would be in a different 
location to the second intramolecular disulphide bond of Alt a 1 (Cys104-Cys116) (Chruszcz et al. 2012).

Five of the six Cys residues present in Ecp4 and MiAMP1 were found to be conserved. In MiAMP1, all six Cys residues are known to form intramolecular disulphide bonds (Cys11Cys65, Cys21-Cys76, and Cys23-Cys49) (McManus et al. 1999). Inspection of the predicted Ecp4 structure, which was modeled using MiAMP1 as a template, suggests that two of the conserved

Table 1. Apoplastic small secreted proteins (SSPs) of Cladosporium fulvum produced during colonization of susceptible tomato (Solanum lycopersicum cv. Heinz-Cf-0) $)^{\mathrm{a}}$

\begin{tabular}{|c|c|c|c|c|}
\hline SSP name & GenBank accession no. & Protein length (aa) & No. cysteine residues ${ }^{b}$ & Brief description and functional domains \\
\hline Avr2 & CAD16675 & 78 & 8 & $\begin{array}{l}\text { Avr effector recognized by the } \mathrm{Cf}-2 \text { immune } \\
\text { receptor. Cysteine protease inhibitor. } \\
\text { Similar to hypothetical proteins }\end{array}$ \\
\hline Avr4 & CAA55403 & 135 & 8 & $\begin{array}{l}\text { Avr effector recognized by the Cf- } 4 \text { immune } \\
\text { receptor. Protects cell wall chitin. CBM_14 } \\
\text { domain (PF01607) }\end{array}$ \\
\hline Avr4E & AAT28196 & 121 & 6 & $\begin{array}{l}\text { Avr effector recognized by the } \mathrm{Cf}-4 \mathrm{E} \\
\text { immune receptor. Novel }\end{array}$ \\
\hline Avr5 & AHY02126 & 103 & 10 & $\begin{array}{l}\text { Avr effector recognized by the Cf- } 5 \text { immune } \\
\text { receptor. Novel }\end{array}$ \\
\hline Avr9 & $\mathrm{P} 22287$ & 63 & 6 & $\begin{array}{l}\text { Avr effector recognized by the Cf- } 9 \text { immune } \\
\text { receptor. Cysteine knot fold. Similar to } \\
\text { hypothetical proteins }\end{array}$ \\
\hline Ecp1 & CAA78400 & 96 & 8 & $\begin{array}{l}\text { Avr effector recognized by the Cf-Ecp } 1 \\
\text { immune receptor. Similar to hypothetical } \\
\text { proteins }\end{array}$ \\
\hline Ecp2-1 & CAA78401 & 165 & 4 & $\begin{array}{l}\text { Avr effector recognized by the Cf-Ecp2-1 } \\
\text { immune receptor. Hce } 2 \text { domain (PF14856) }\end{array}$ \\
\hline Ecp4 & CAC01609 & 119 & 6 & $\begin{array}{l}\text { Avr effector recognized by the Cf-Ecp } 4 \\
\text { immune receptor. Predicted } \beta / \gamma \text {-crystallin- } \\
\text { like fold. Similar to hypothetical proteins. } \\
\text { Paralog of Ecp7. Homolog of Ecp } 29\end{array}$ \\
\hline Ecp5 & CAC01610 & 115 & 6 & $\begin{array}{l}\text { Avr effector recognized by the Cf-Ecp5 } \\
\text { immune receptor. Similar to hypothetical } \\
\text { proteins }\end{array}$ \\
\hline Ecp6 & AQA29283 & 222 & 8 & $\begin{array}{l}\text { Avr effector recognized by the Cf-Ecp6 } \\
\text { immune receptor. Suppresses chitin- } \\
\text { triggered immunity. Three LysM domains } \\
\text { (PF01476) }\end{array}$ \\
\hline Ecp7 & AQA29284 & 116 & 6 & $\begin{array}{l}\text { Predicted } \beta / \gamma \text {-crystallin-like fold. Similar to } \\
\text { hypothetical proteins. Paralog of Ecp } 4 \text {. } \\
\text { Homolog of Ecp } 29\end{array}$ \\
\hline Ecp8 & AQA29209 & 105 & 8 & Possible Avr effector. Novel \\
\hline Ecp9-1 & AQA29212 & 88 & 6 & $\begin{array}{l}\text { Possible Avr effector. Similar to hypothetical } \\
\text { proteins. Paralog of Ecp9-9 }\end{array}$ \\
\hline Ecp9-9 & AQA29252 & 90 & 6 & $\begin{array}{l}\text { Similar to hypothetical proteins. Paralog of } \\
\text { Ecp9-1 }\end{array}$ \\
\hline Ecp10-1 & AQA29217 & 70 & 6 & $\begin{array}{l}\text { Possible Avr effector. Similar to hypothetical } \\
\text { proteins. Paralog of Ecp10-2 }\end{array}$ \\
\hline Ecp10-2 & AQA29234 & 67 & 6 & $\begin{array}{l}\text { Similar to hypothetical proteins. Paralog of } \\
\text { Ecp10-1 }\end{array}$ \\
\hline Ecp11-1 & AQA29221 & 165 & 10 & $\begin{array}{l}\text { Possible Avr effector. Homolog of the } \\
\text { AvrLm3 Avr effector from Leptosphaeria } \\
\text { maculans }\end{array}$ \\
\hline Ecp12 & AQA29229 & 133 & 8 & $\begin{array}{l}\text { Possible Avr effector. Similar to hypothetical } \\
\text { proteins }\end{array}$ \\
\hline Ecp13 & AQA29236 & 73 & 10 & $\begin{array}{l}\text { Possible Avr effector. Similar to hypothetical } \\
\text { proteins }\end{array}$ \\
\hline Ecp14-1 & AQA29258 & 206 & 12 & Possible Avr effector. Class II hydrophobin \\
\hline Ecp15 & AQA29262 & 131 & 8 & $\begin{array}{l}\text { Possible Avr effector. Similar to hypothetical } \\
\text { proteins }\end{array}$ \\
\hline Ecp16 & AQA29251 & 101 & 8 & Possible Avr effector. Novel \\
\hline Ecp17 & AQA29222 & 62 & 6 & Possible Avr effector. Novel \\
\hline Ecp18 & AQA29206 & 81 & 10 & Novel \\
\hline Ecp19-1 & AQA29207 & 162 & 8 & $\begin{array}{l}\text { Similar to hypothetical proteins. Paralog of } \\
\text { Ecp19-2 }\end{array}$ \\
\hline Ecp19-2 & AQA29219 & 130 & 8 & $\begin{array}{l}\text { Similar to hypothetical proteins. Paralog of } \\
\text { Ecp19-1 }\end{array}$ \\
\hline Ecp20-1 & AQA29208 & 166 & 4 & $\begin{array}{l}\text { Predicted Alt a } 1 \text { allergen-like fold. Similar } \\
\text { to hypothetical proteins. Paralog of Ecp20- } \\
2 \text { and Ecp } 20-3\end{array}$ \\
\hline Ecp20-2 & AQA29228 & 149 & 4 & $\begin{array}{l}\text { Predicted Alt a } 1 \text { allergen-like fold. Similar } \\
\text { to hypothetical proteins. Paralog of Ecp20- } \\
1 \text { and Ecp20-3 }\end{array}$ \\
\hline
\end{tabular}

(Continued on next page)

\footnotetext{
a With the exception of Ecp56-Ecp60-1, all SSPs are encoded by genes that are induced in planta. Ecp = extracellular protein; aa = amino acids; Avr = Avirulence.
}

b Number of cysteine residues in each mature SSP (i.e., following their predicted N-terminal signal peptide cleavage site). 
Cys pairs, Cys16/Cys84 and Cys35/Cys67, form intramolecular disulphide bonds. Although not conserved, the sixth Cys residue in Ecp4, Cys57, still appears to be in a favorable position for disulphide bond formation with Cys99. All six Cys residues in Ecp4 are conserved across Ecp7 and Ecp29 (CTR), although the latter has an additional pair of Cys residues.
For Ecp28-3 and KP6 3 , six conserved Cys residues, which are also present in Ecp28-1 and Ecp28-2, were identified. In $\mathrm{KP} 6 \beta$, these six Cys residues are known to form three intramolecular disulphide bonds (Cys9-Cys74, Cys11-Cys64, and Cys29-Cys46) (Allen et al. 2013a). The predicted Ecp28-3 structure, which was modeled using KP6 $\beta$ as a template, suggests

Table 1. (Continued from previous page)

\begin{tabular}{|c|c|c|c|c|}
\hline SSP name & GenBank accession no. & Protein length (aa) & No. cysteine residues ${ }^{b}$ & Brief description and functional domains \\
\hline Ecp20-3 & AQA29267 & 153 & 4 & $\begin{array}{l}\text { Predicted Alt a } 1 \text { allergen-like fold. Similar } \\
\text { to hypothetical proteins. Paralog of Ecp20-1 } \\
\text { and Ecp20-2 }\end{array}$ \\
\hline Ecp21-1 & AQA29210 & 184 & 8 & Similar to hypothetical proteins \\
\hline Ecp22 & AQA29211 & 161 & 8 & Similar to hypothetical proteins \\
\hline Ecp23 & AQA29215 & 91 & 4 & Novel \\
\hline Ecp24-1 & AQA29216 & 92 & 4 & Homolog of Ecp24-2. Novel \\
\hline Ecp24-2 & AQA29265 & 77 & 1 & Homolog of Ecp24-1. Novel \\
\hline Ecp25 & AQA29218 & 79 & 8 & Similar to hypothetical proteins \\
\hline Ecp26 & AQA29223 & 65 & 6 & Similar to hypothetical proteins \\
\hline Ecp27 & AQA29225 & 67 & 4 & Similar to hypothetical proteins \\
\hline Ecp28-1 & AQA29227 & 101 & 6 & $\begin{array}{l}\text { Predicted KP6-like fold. Similar to } \\
\text { hypothetical proteins. Homolog of Ecp28-2, } \\
\text { Ecp28-3 and Ecp29 }\end{array}$ \\
\hline Ecp28-2 & AQA29259 & 105 & 8 & $\begin{array}{l}\text { Predicted KP6-like fold. Similar to } \\
\text { hypothetical proteins. Paralog of Ecp28-3. } \\
\text { Homolog of Ecp28-1 and Ecp29 }\end{array}$ \\
\hline Ecp28-3 & AQA29261 & 105 & 8 & $\begin{array}{l}\text { Predicted KP6-like fold. Similar to } \\
\text { hypothetical proteins. Paralog of Ecp28-2. } \\
\text { Homolog of Ecp28-1 and Ecp29 }\end{array}$ \\
\hline Ecp29 & AQA29274 & 266 & 14 & $\begin{array}{l}\text { Amino }(\mathrm{N}) \text {-terminal domain has a predicted } \\
\text { KP6-like fold. Carboxyl }(\mathrm{C}) \text {-terminal } \\
\text { domain has a predicted } \beta / \gamma \text {-crystallin-like } \\
\text { fold. Similar to hypothetical proteins. } \\
\text { Homolog of Ecp4, Ecp7, Ecp28-1, Ecp28-2 } \\
\text { and Ecp28-3 }\end{array}$ \\
\hline Ecp30 & AQA29247 & 141 & 6 & $\begin{array}{l}\text { Predicted } \beta / \gamma \text {-crystallin-like fold. Similar to } \\
\text { hypothetical proteins }\end{array}$ \\
\hline Ecp31 & AQA29230 & 93 & 10 & Novel \\
\hline Ecp32-1 & AQA29233 & 197 & 4 & IgE-binding protein. Paralog of Ecp32-2 \\
\hline Ecp32-2 & AQA29272 & 195 & 2 & IgE-binding protein. Paralog of Ecp32-1 \\
\hline Ecp33 & AQA29237 & 210 & 8 & Similar to hypothetical proteins \\
\hline Ecp34 & AQA29238 & 92 & 8 & Novel \\
\hline Ecp35 & AQA29239 & 70 & 8 & Novel \\
\hline Ecp36-1 & AQA29240 & 73 & 10 & Similar to hypothetical proteins \\
\hline Ecp37 & AQA29243 & 79 & 6 & Novel \\
\hline Ecp38 & AQA29244 & 84 & 10 & Novel \\
\hline Ecp39 & AQA29245 & 63 & 8 & Similar to hypothetical proteins \\
\hline Ecp40 & AQA29250 & 92 & 8 & Similar to hypothetical proteins \\
\hline Ecp41 & AQA29253 & 133 & 9 & Similar to hypothetical proteins \\
\hline Ecp42 & AQA29254 & 128 & 14 & Similar to hypothetical proteins \\
\hline Ecp43-1 & AQA29260 & 94 & 10 & Similar to hypothetical proteins \\
\hline Ecp44 & AQA29263 & 146 & 4 & $\begin{array}{l}\text { Similar to hypothetical proteins. GPI- } \\
\text { anchored domain (PF10342) }\end{array}$ \\
\hline Ecp45 & AQA29264 & 146 & 4 & $\begin{array}{l}\text { Cerato-platanin. Cerato-platanin domain } \\
\text { (PF07249) }\end{array}$ \\
\hline Ecp46 & AQA29266 & 164 & 2 & Similar to hypothetical proteins \\
\hline Ecp47 & AQA29268 & 148 & 10 & Similar to hypothetical proteins \\
\hline Ecp48 & AQA29269 & 78 & 8 & Similar to hypothetical proteins \\
\hline Ecp49-1 & AQA29270 & 104 & 7 & Similar to hypothetical proteins \\
\hline Ecp50-1 & AQA29271 & 182 & 0 & $\begin{array}{l}\text { Hydrophobic surface-binding protein. HsbA } \\
\text { domain (PF12296) }\end{array}$ \\
\hline Ecp51 & AQA29273 & 238 & 8 & Similar to hypothetical proteins \\
\hline Ecp52 & AQA29275 & 170 & 4 & Similar to hypothetical proteins \\
\hline Ecp53-1 & AQA29276 & 176 & 2 & Similar to hypothetical proteins \\
\hline Ecp54-1 & AQA29278 & 160 & 11 & Similar to hypothetical proteins \\
\hline Ecp55 & AQA29279 & 239 & 20 & Similar to hypothetical proteins \\
\hline Ecp56 & AQA29281 & 60 & 6 & Novel \\
\hline Ecp57-1 & AQA29324 & 285 & 5 & CAP domain (PF00188) \\
\hline Ecp58-1 & AQA29297 & 196 & 4 & Similar to hypothetical proteins \\
\hline Ecp59-1 & AQA29364 & 128 & 2 & Similar to hypothetical proteins \\
\hline Ecp60-1 & AQA29321 & 249 & 6 & Similar to hypothetical proteins \\
\hline CfPhiA-1 & AQA29214 & 195 & 4 & Phialide protein. Paralog of CfPhiA-2 \\
\hline CfPhiA-2 & AQA29256 & 218 & 6 & Phialide protein. Paralog of CfPhiA-1 \\
\hline
\end{tabular}


that the three conserved Cys pairs (Cys7/Cys76, Cys9/Cys66, and Cys26/Cys47) form intramolecular disulphide bonds. Both Ecp282 and Ecp28-3 possess an additional set of Cys residues (Cys1 and Cys60). Cys1 of Ecp28-3 is located at the extreme N-terminus, which, if flexible, would be expected to make contact with Cys60, located at the base of one of the predicted $\alpha$-helices.

\section{Most apoplastic in planta-induced SSPs}

of $C$. fulvum lack an ortholog in Dothistroma septosporum.

Of the fungi for which a genome sequence is so far available, D. septosporum, which causes red band needle blight disease of pine, is the most closely related to C. fulvum (de Wit et al. 2012). Recently, it was shown that homologs of Avr4, Ecp2-1, and Ecp6 are encoded by the genome of D. septosporum (de Wit et al. 2012). The same genome was also found to carry pseudogenes of Ecp4 and Ecp5 (de Wit et al. 2012). This raises the possibility that, despite differences in host type (angiosperm versus gymnosperm) and mode of host infection (biotroph versus hemibiotroph), substantial overlap exists between the apoplastic SSP effector sets of $C$. fulvum and D. septosporum. We set out to investigate this possibility further. To accomplish this, reciprocal BLASTp and tBLASTn searches were used to determine whether the predicted D. septosporum protein catalog and genome (de Wit et al. 2012) carry homologs of the 70 C. fulvum apoplastic in planta-induced SSPs and their encoding genes, respectively. For 43 of the 70 SSPs, no homologs were identified. Four more showed limited homology to D. septosporum SSPs, while five others had homology to pseudogenes. The remaining 18 SSPs had likely orthologs in D. septosporum. However, of these, only 11 were up-regulated during infection of pine (Bradshaw et al. 2016). More specifically, these are the likely orthologs of Ecp2-1, Ecp6, Ecp13, Ecp19-2, Ecp20-1, Ecp20-2, Ecp20-3, Ecp45, Ecp53-1, Ecp55, and CfPhiA-2.

\section{Nine apoplastic in planta-induced SSPs of $C$. fulvum trigger an HR in specific accessions of tomato.}

To identify new sources of resistance against $C$. fulvum, wild accessions of tomato were screened for their ability to recognize apoplastic in planta-induced SSPs, using the PVX-based transient expression system (Hammond-Kosack et al. 1995; Takken et al. 2000). In this experiment, recombinant viruses were delivered through agroinfection for local (toothpick wounding) or systemic (cotyledon infiltration) expression of SSPs in tomato, with the pathogenesis-related 1A (PR1A) signal peptide of tobacco (Nicotiana tabacum) used to direct secretion of these proteins into the tomato leaf apoplast. Plants that showed a chlorotic or necrotic HR were deemed to have recognized an SSP as an Avr determinant.

As a starting point, 25 predominantly wild accessions of tomato (Supplementary Table S3) were screened for their ability to recognize 41 in planta-induced SSPs using the PVX agroinfection method based on toothpick wounding (Luderer et al. 2002a; Takken et al. 2000). This set of 41 primarily comprises those SSPs with the highest level of expression in planta, as based on pre-existing RNA-Seq data (i.e., those SSPs encoded by a gene with a peak in planta fragments per kilobase of exons per million fragments mapped [FPKM] value of $>300$ ). None of the

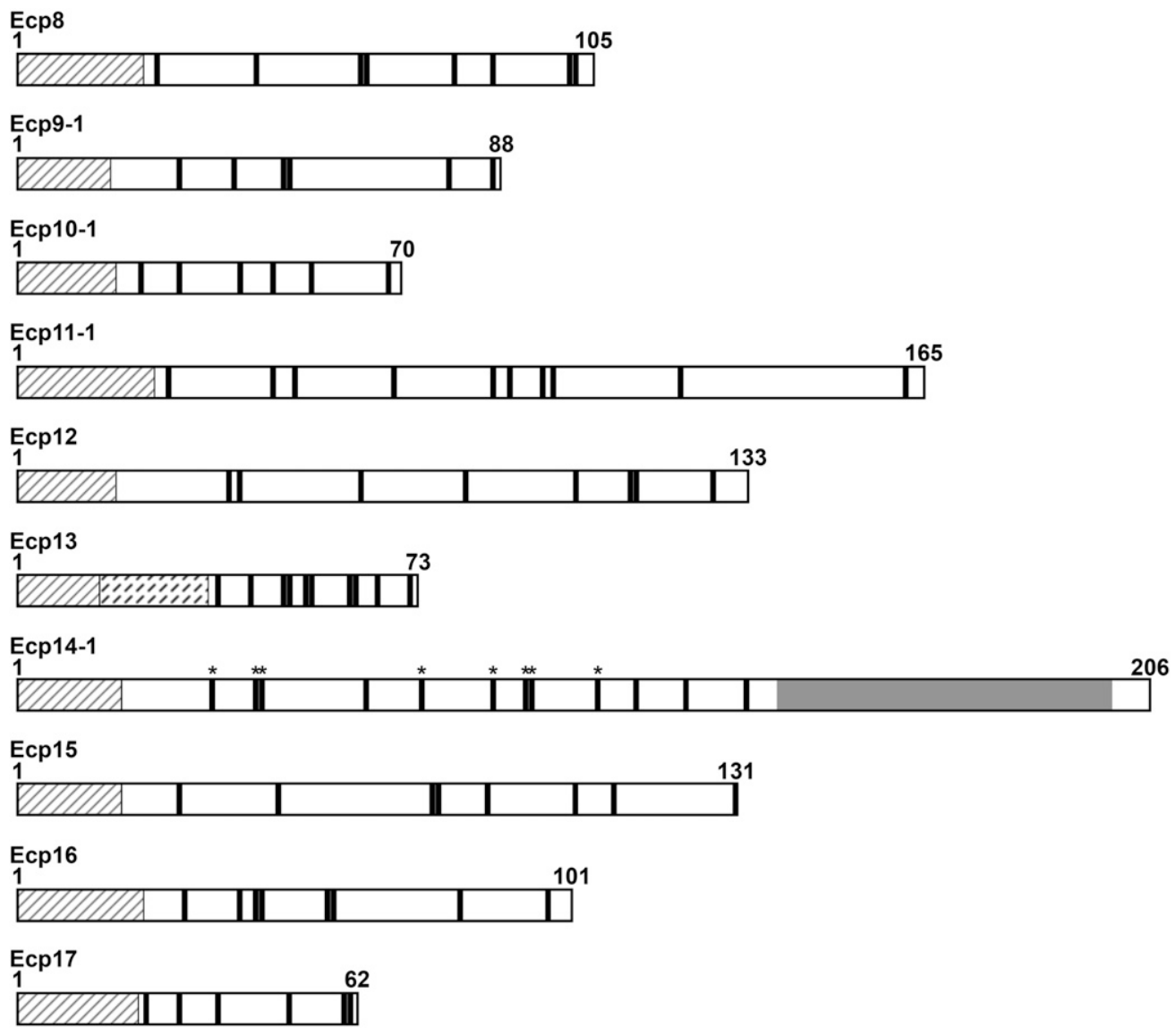

Fig. 1. Schematic representation of 10 apoplastic in planta-induced small secreted proteins (SSPs) from Cladosporium fulvum 0WU that trigger a hypersensitive response (HR) in one or more specific accessions of tomato. All 10 SSPs are small, cysteine-rich, and are predicted to possess an amino (N)-terminal signal peptide for extracellular targeting to the tomato leaf apoplast. The predicted signal peptide of each SSP is indicated by black diagonal lines. Cysteine residues are indicated by thick vertical bars. Numbers indicate the first and last amino-acid residue of each protein. The predicted propeptide domain of Ecp13, ending with a predicted kexin protease cleavage site, is indicated by black dashed diagonal lines. A glycine/leucine-rich region present in Ecp14-1 is shaded gray. Cysteine residues of Ecp14-1 that are conserved with fungal hydrophobin proteins are indicated by asterisks. 
10 known Avr effectors are among the 41, since these SSPs already have a matching $\mathrm{Cf}$ immune receptor gene. Furthermore, a small number of highly expressed SSPs could not be tested, as the genes encoding these proteins could not be cloned from cDNA in time for use in the experiment. A fully expanded leaf from one to three representative plants of each accession was inoculated via toothpick wounding on each side of the main vein, and the presence or absence of an HR was scored at $10 \mathrm{dpi}$. At the same time, S. lycopersicum cv. MM-Cf-0 (no Cf immune receptor genes [Tigchelaar 1984]) was screened to determine whether any of the SSPs trigger a nonspecific HR. Likewise, accessions carrying only the $C f-1, C f-3, C f-6, C f-9 B, C f-11$, or $C f$-Ecp3 immune receptor gene were screened to determine whether any of the SSPs represent one of the yet-unknown Avr effectors Avr1, Avr3, Avr6, Avr9B, Avr11, or Ecp3. As positive controls, S. lycopersicum cv. MM-Cf-5, which carries only the $C f-5$ immune receptor (Tigchelaar 1984), as well as the landrace accession CGN 18399 (S. lycopersicum var. cerasiforme), from which the $C f-5$ gene was originally identified (Kerr et al. 1971), were screened for their ability to recognize the Avr effector Avr5 (Mesarich et al. 2014). Empty vector was used as a negative control to confirm that PVX alone does not trigger a nonspecific HR. For this experiment, recognition of an SSP was deemed to have occurred if an HR was triggered at one or both of the toothpickwounding sites on a given tomato leaf.

As expected, the empty vector (negative control) failed to trigger an HR in any tomato accession tested, while Avr5 (positive control) was recognized by only MM-Cf-5 and CGN 18399 (Supplementary Fig. S4), indicating that the PVX agroinfection method is functional, and that no other accessions carry the $C f-5$ immune receptor gene. Ten of the 41 SSPs (Ecp8, Ecp9-1, Ecp10-1, Ecp11-1, Ecp12, Ecp13, Ecp14-1, Ecp15, Ecp16, and Ecp17) were recognized by one to eight predominantly wild accessions of tomato, with HRs ranging from weak chlorosis to strong necrosis. Furthermore, 15 of the 25 accessions recognized between one and four of the 10 SSPs. Importantly, none of the 10 SSPs triggered an $\mathrm{HR}$ in MM-Cf-0, suggesting that the observed responses were specific to the accessions tested. None of the accessions carrying the $C f-1, C f-3, C f-6, C f-9 B, C f-11$, or $C f-E c p 3$ immune receptor gene recognized any of the SSPs, indicating that these proteins do not represent the Avr effectors Avr1, Avr3, Avr6, Avr9B, Avr11, or Ecp3. A schematic of the $10 \mathrm{HR}$-eliciting SSPs is shown in Figure 1.

To further confirm recognition of the 10 SSPs, each was screened for its ability to trigger a systemic HR in the same responding tomato accessions, using the PVX agroinfection method, based on cotyledon infiltration (Mesarich et al. 2014). Here, both cotyledons of five independent plants were infiltrated, and the presence or absence of an HR was scored at $21 \mathrm{dpi}$. Consistent with the agroinfection assay based on toothpick wounding, the empty vector (negative control) did not trigger an HR in any accession tested (Fig. 2; Supplementary Fig. S5). Similarly, none of the SSPs triggered an HR in MM-Cf-0 (Supplementary Fig. S6). For Ecp8, Ecp12, Ecp13, Ecp14-1, Ecp15, and Ecp16, recognition could be confirmed across all responding accessions identified in the toothpick-wounding agroinfection assay (Fig. 2; Supplementary Fig. S7). Recognition could also be confirmed across most, but not all, previously identified accessions for Ecp9-1, Ecp10-1, and Ecp11-1 (Fig. 2). Indeed, Ecp9-1, Ecp10-1, and Ecp11-1 only failed to trigger an HR in accessions CGN 15392 (Solanum arcanum), CGN 14356 (Solanum peruvianum), and CGN 14357 (Solanum corneliomuelleri), respectively. In all responding accessions, the systemic HR involved weak to strong necrosis and was typically associated with moderate to severe stunting (Fig. 2; Supplementary Fig. S8). The recognition of only one SSP, Ecp17, could not be confirmed (CGN 24034). In some cases, the recognition of an SSP could not be observed across all five plants of a given accession representing S. corneliomuelleri (CGN 14357 and CGN 15793), S. peruvianum (CGN 14355, CGN 14356 and CGN 24192), and S. pimpinellifolium (CGN 15946) (Fig. 2). This is not surprising, because both $S$. corneliomuelleri and $S$. peruvianum are typically self-incompatible, while $S$. pimpinellifolium is facultatively selfcompatible (Peralta and Spooner 2006). In other words, genetic variation is expected to exist between representatives of accessions from these species, with this variation extending to the presence or absence of corresponding functional $\mathrm{Cf}$ immune receptor gene alleles. This may explain why Ecp17 gave such a strong HR in accession CGN 24034 using the toothpick assay but no HR in the agroinfiltration assay. This may also be true for Ecp9-1 on CGN 15392 (S. arcanum, typically self-incompatible), Ecp10-1 on CGN 14356, and Ecp11-1 on CGN 14357.

\section{Tomato accessions that recognize apoplastic} in planta-induced SSPs are resistant to $C$. fulvum.

To determine whether the accessions of tomato that recognize apoplastic in planta-induced SSPs are resistant to C. fulvum, each, along with $S$. lycopersicum cv. MM-Cf-0, was inoculated with strain 2.4.5.9.11 IPO of this fungus, and symptoms were inspected on leaves from three independent plants at $14 \mathrm{dpi}$. Strain 2.4.5.9.11 IPO carries genes corresponding to all nine HReliciting SSPs (discussed below) but lacks a functional copy of the previously cloned Avr2, Avr4, Avr4E, Avr5, and Avr9 Avr effector genes (Mesarich et al. 2014; Stergiopoulos et al. 2007). As expected, $S$. lycopersicum cv. MM-Cf-0 was susceptible to 2.4.5.9.11 IPO (Supplementary Fig. S9). In contrast, all other tomato accessions tested were resistant to this strain. For accessions CGN 14474 (S. lycopersicum) and CGN 15820 (S. lycopersicum $\times$ cheesmaniae), this resistance was observed across only two of the three independent plants. While resistant to $C$. fulvum, we cannot exclude the possibility that the set of resistant tomato accessions carries one or more of, for example, the $\mathrm{Cf}$ immune receptor genes $C f-1, C f-3, C f-6, C f-9 B, C f-E c p 1, C f-E c p 2-1, C f-E c p 3, C f-E c p 4$, $C f-E c p 5$, and $C f-E c p 6$.

\section{Seven HR-eliciting SSPs have one or more homologs in other fungal species, while three HR-eliciting SSPs have one or more paralogs in C. fulvum.}

To identify homologs of the HR-eliciting SSPs in other fungi, each was screened against the publicly available protein sequence databases at NCBI and JGI using BLASTp. Additionally, in those cases in which no protein homolog could be identified, SSPs were screened against the collection of fungal genome sequences present at JGI using tBLASTn (i.e., to identify homologs without a gene prediction). Except for Ecp8 and Ecp16, homologs of all HR-eliciting SSPs were identified in other fungal species. For Ecp9-1, homologs were identified in the Dothideomycetes Pseudocercospora fijiensis (black sigatoka disease of banana), Septoria musiva and Septoria populicola (leaf spot and canker diseases of poplar), Teratosphaeria nubilosa (leaf spot of Eucalyptus spp.) and Zasmidium cellare (saprobic wine cellar fungus), as well as eight Sordariomycete species (Supplementary Fig. S10). Eight paralogs of Ecp9-1 were found to be encoded by the genome of C. fulvum 0WU (Ecp9-2 to Ecp9-9) (Supplementary Fig. S11A), with one pseudogene also identified (Ecp9-10; result not shown). A similar expansion was found in the Sordariomycete Claviceps purpurea (ergot disease of cereals).

Homologs of Ecp10-1 were identified in the Dothideomycetes Pseudocercospora eumusae and Pseudocercospora musae (eumusae leaf spot and yellow sigatoka disease of banana, respectively), A. alternata, Septoria musiva, Septoria populicola, T. nubilosa, and Zasmidium cellare as well as Zymoseptoria ardabiliae, Zymoseptoria pseudotritici, and Zymoseptoria tritici (leaf blotch diseases of grasses), Venturia inaequalis and Venturia pirina (apple and pear scab disease, respectively), Clathrospora 
elynae (found growing on curved sedge), Cochliobolus sativus and Cochliobolus victoriae (cereal pathogens), Pyrenophora teres f. teres (net blotch disease of barley), Pyrenophora tritici-repentis (tan spot disease of wheat), and Setosphaeria turcica (northern corn leaf blight disease) (Supplementary Fig. S12; Supplementary Information S2). Homologs of Ecp10-1 were also identified in several Sordariomycete fungi. Interestingly, Ecp10-1 homologs were found to be massively expanded in $V$. inaequalis and $V$. pirina, which is not uncommon for effector candidates from these fungi (Deng et al. 2017). Smaller expansions were also identified in other fungal plant pathogens. Two paralogs of Ecp101 (Ecp10-2 and Ecp10-3) were found to be encoded by the genome of $C$. fulvum $0 \mathrm{WU}$.

Homologs of the remaining SSPs were only identified in Dothideomycete fungi. Ecp11-1 was found to have homology to AvrLm3, an Avr effector protein from Leptosphaeria maculans (blackleg disease of Brassica species) (Plissonneau et al. 2016) as well as two proteins from $Z$. ardabiliae (Fig. 3). A single pseudogene of Ecp11-1 (Ecp11-2) was also identified in the genome of C. fulvum 0WU (result not shown). Ecp12 was found to have multiple homologs in Septoria musiva and Septoria populicola, with the homologous Cys-rich domain occurring once, or as two or three tandem repeats (Supplementary Fig. S13), as has been found for several other effectors from plant-associated organisms (Mesarich et al. 2015). Homologs of Ecp13 were identified in D. septosporum, P. fijiensis, Septoria musiva, and Cercospora zeae-maydis (gray leaf spot disease of maize) (Supplementary Fig. S14), while homologs of Ecp14-1 were found in Cercospora zeae-maydis, D. septosporum, P. eumusae P. fijiensis, P. musae, Septoria musiva, Septoria populicola, T. nubilosa, Trypethelium eluteriae (lichen-forming fungus), Z. ardabiliae, Zymoseptoria brevis (leaf blotch disease of barley), Z. pseudotritici, Z. tritici,
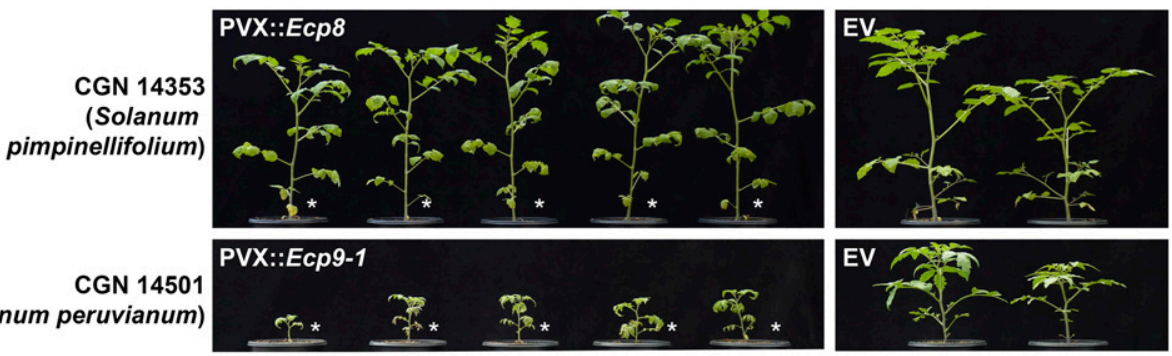

(Solanum peruvianum)
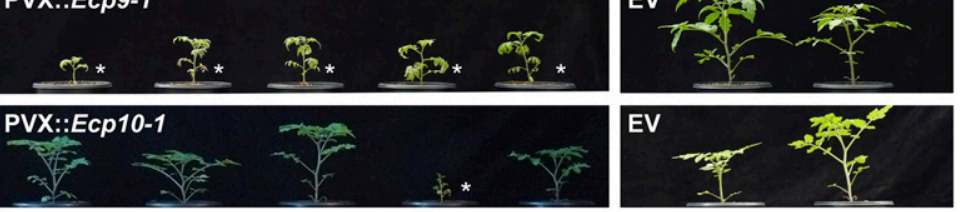

cornetic
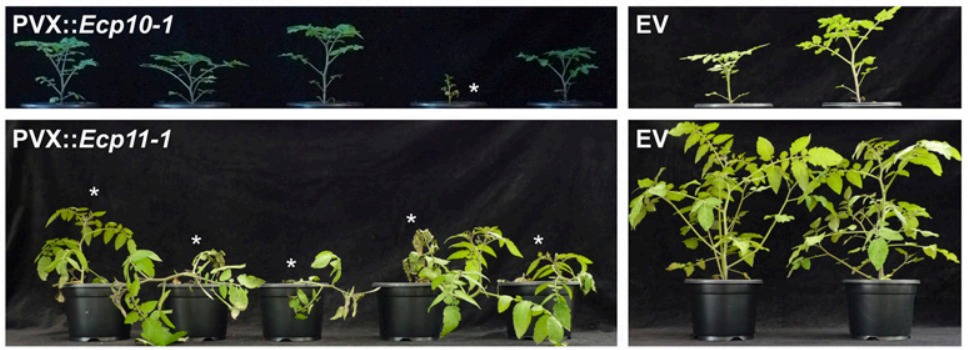

S. pimpinellifolium

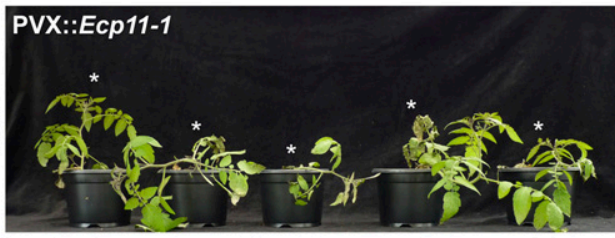

PVX::Ecp12

CGN 14355 (S. peruvianum)
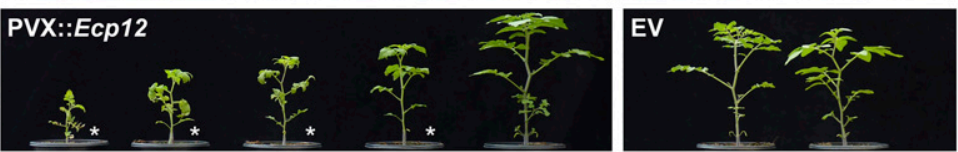

CGN 14352
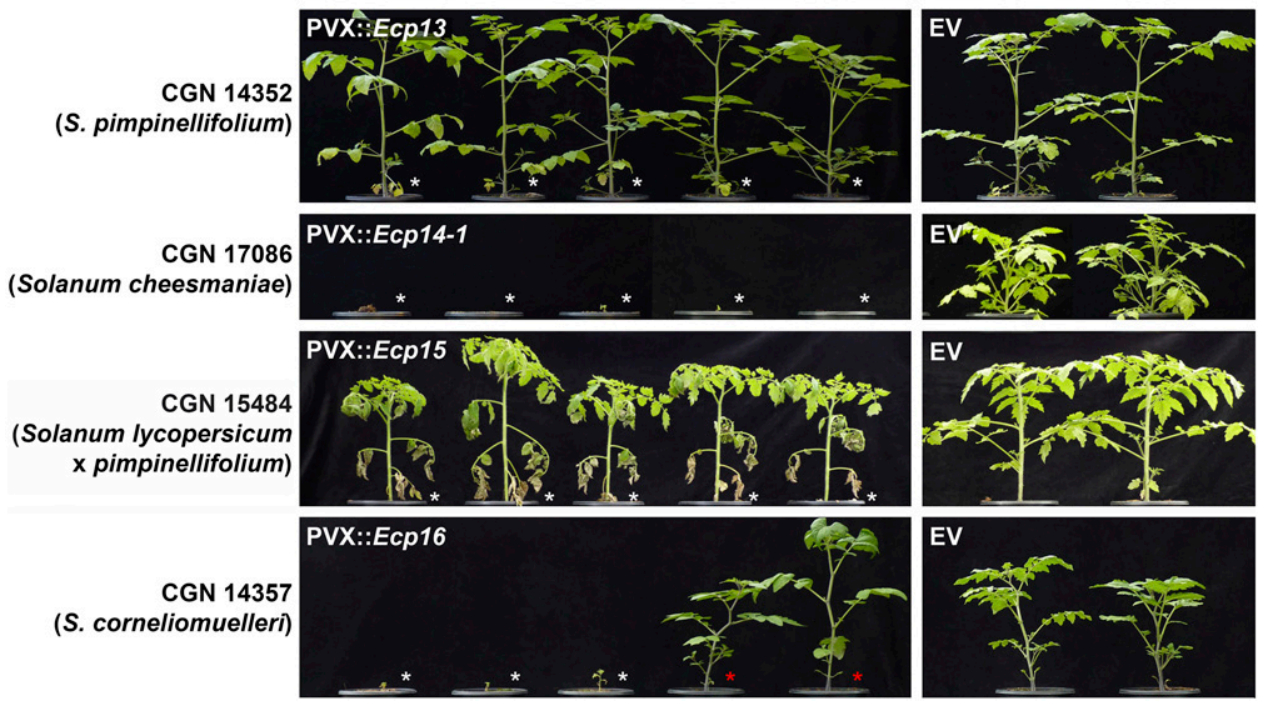

Fig. 2. Nine apoplastic in planta-induced small secreted proteins (SSPs) of Cladosporium fulvum 0WU trigger a systemic hypersensitive response (HR) in one or more specific accessions of tomato. Selected examples are shown. SSPs were systemically produced in five representatives of each tomato accession (left) using the Potato virus $X$ (PVX) transient expression system. Recombinant viruses were delivered by Agrobacterium tumefaciens (agroinfection) through cotyledon infiltration at 10 days post-seed germination. Two representatives of each tomato accession were inoculated with PVX alone (pSfinx empty vector [EV]) (right). White asterisks indicate plants exhibiting a systemic chlorotic or necrotic HR; red asterisks indicate plants without obvious mosaic symptoms (i.e., not infected with PVX). Photographs were taken at 21 days postinfiltration. 
and Zasmidium cellare, with most, including C. fulvum, possessing a paralog (Supplementary Fig. S15). A single pseudogene of Ecp14-1 (Ecp14-3) was identified in the genome of C. fulvum 0WU (result not shown). For Ecp15, homologs were found in $P$. fijiensis, P. musae, and Z. ardabiliae (Supplementary Fig. S16).

\section{Genes encoding HR-eliciting SSPs are induced in planta.}

RNA-Seq FPKM values suggested that all genes encoding an HR-eliciting SSP of C. fulvum, like those encoding all previously identified Avr effectors of this fungus (Mesarich et al. 2014), are induced during infection of susceptible tomato when compared with expression during growth in vitro in PDB or Gamborg B5 liquid media. To confirm this expression profile, a reverse-transcription quantitative real-time polymerase chain reaction (RT-qrtPCR) experiment was performed. Indeed, all genes encoding an HR-eliciting SSP were found to be induced during infection of susceptible tomato when compared with expression during growth in vitro in PDB or Gamborg B5 liquid media (Fig. 4).
Most genes encoding an HR-eliciting SSP are associated with repetitive elements.

It is common for $C$. fulvum effector genes to be flanked by a mosaic of repetitive elements in the genome of strain 0WU (de Wit et al. 2012; Mesarich et al. 2014). It has been proposed that these elements may assist in the deletion of Avr effector genes following $\mathrm{Cf}$ immune receptor gene-imposed selection pressure (Mesarich et al. 2014). To determine whether repetitive elements also flank genes encoding the HR-eliciting SSPs, the genome scaffolds harboring each of these genes was screened for repetitive sequence across the $C$. fulvum $0 \mathrm{WU}$ genome using BLASTn. Six of the nine SSP genes (Ecp8, Ecp9-1, Ecp10-1, Ecp11-1,Ecp 12, and Ecp 15) were found to be associated with repetitive elements at both their 5 and 3' flanks (Supplementary Fig. S17). Furthermore, the same six genes were found to reside on small genome scaffolds of less than $35 \mathrm{~kb}$ in length (Supplementary Table S4). The latter suggests that the scaffolds harboring these genes are surrounded by even larger flanking repetitive elements, with these elements anticipated to have hampered a larger scaffold assembly (de Wit et al. 2012). The
Ecp11-1_AQA29221_Clafu

AvrLm3 ALS92799 Lepma

Scaffold_667:56 $\overline{4} 24-56906$ Zymar

Scaffold_1237:24046-24549 _zymar

Ecp11-1_AQA29221_Clafu

AvrLm3 ALS92799 Lepma

Scaffold $667: 56 \overline{4} 24-56906$ Zymar

Scaffold_1237:24046-24549_Zymar

Ecp11-1_AQA29221_Clafu

AvrLm3 ALS92799 Lepma

Scaffold_667:56 $\overline{4} 24-56906$ Zymar

Scaffold_1237:24046-24549__ymar
MLSSAKTLWLLLLSMLAYTTKPAYSLDCKAVALKWVHQFRIPGGDNCNFYCSYDSLYQQF 60 MLKPTKVIQILFLLFT-AFFARTCALECHAVAFSSDHQFSLGRNEDCNLYCSKNSMLSIF 59 MERQNSAMALLLLAFL-GLVLPAFÄHDCRSIALSYEARAVAGEFEDCRQYIDVNKMLADM 59 MGQQFSA-LALLLAFL-GTIAPVFSHDCRAISITYEKRERIPPYQDCAQYCSLKGMIDEM 58 ${ }_{\star}^{\star}:{ }^{\star}: \quad: \quad{ }^{\star}::::: \quad: \quad:{ }^{\star}{ }^{*} \quad: \quad:$

NL--------WKKNDACQGADGFSTAIPKIQEAPCS-DCPGSKTCICSVQATAWRVRNG 110 SRV-------LPLDDPCQGDDGFSSLTATIDQISCDTGC----QCRCSVHATAWRVHKS 107 NRQLVNLPDLDPPRADICMGDDGFGTYNTGCEFPACKQNC--KKNCRCWVRWTAWRVHKE 117 NKRLDPVMTLGYPRADVCQGDDGFSTFASQIDYPRCSGAC--NTDCRCWVRWTAWRVHKE 116

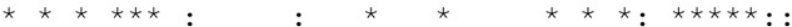

--KWFDGQQWFDCDVKPYTERVLGRRWYDESEADKDIYVGYYSRGFISNDNVHCGSQ- 165 GKRYSRRTGWVSCNLEDYVARITGRPFIPVNGALH----EYFSRGFVSKDEVHCDHQ- 160 N------QGGVSCAIGDFASRLTTKQYKP PNYNGPF--LRTYVLATETNDNVHCGHQR 167 D------QYGASCQVKDYVARLTGKPFVAPNDPIPGGPPYTFVTAIVSNNNVHCKSQ- 167

Fig. 3. Ecp11-1 of Cladosporium fulvum is a homolog of AvrLm3 from Leptosphaeria maculans. Conserved (*) and physicochemically similar (:) amino-acid residues shared between all proteins are shown below the alignment. Cysteine residues are highlighted in bold. The predicted amino $(\mathrm{N})$-terminal signal peptide sequence of each protein is underlined. Clafu $=$ C. fulvum $0 \mathrm{WU}$; Lepma $=$ L. maculans $\mathrm{v} 23.1 .3$; and Zymar $=$ Zymoseptoria ardabiliae STIR04.

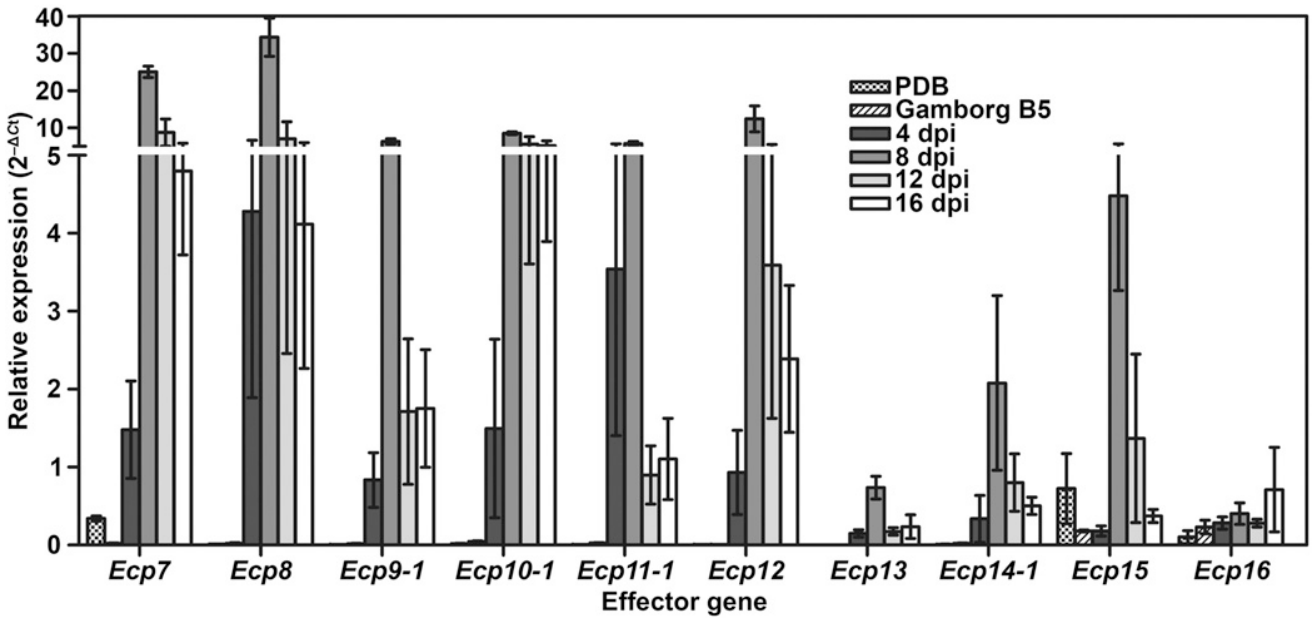

Fig. 4. Genes encoding a hypersensitive response-eliciting small secreted protein (SSP) from Cladosporium fulvum 0WU are induced in planta. Expression was monitored by a reverse-transcription-quantitative real-time polymerase chain reaction experiment in planta during a compatible $C$. fulvum 0WU-Solanum lycopersicum cv. Heinz Cf-0 interaction at 4, 8, 12, and 16 days postinoculation (dpi) as well as during growth of $C$. fulvum $0 \mathrm{WU}$ in vitro in potato-dextrose broth (PDB) and Gamborg B5 liquid media at 4 dpi. The $C$. fulvum actin gene was targeted for normalization of expression, which was calculated using the $2^{-\Delta C \mathrm{t}}$ method. Error bars represent the standard deviation of three biological replicates. 
5' end of Ecp16 is closely associated with repetitive elements and is present at the $5^{\prime}$ end of an approximately $55-\mathrm{kb}$ scaffold. Likewise, Ecp 13 is located at the $3^{\prime}$ end of an approximately $57-\mathrm{kb}$ scaffold, suggesting the presence of $3^{\prime}$ repeats. In contrast to the SSP genes mentioned above, Ecp14-1 is not surrounded by repetitive elements.

\section{Genes encoding an HR-eliciting SSP}

\section{exhibit limited allelic variation between strains.}

It is common for genes encoding C. fulvum Avr effectors to exhibit allelic variation between strains, which is often brought about by selection pressure to avoid recognition by corresponding Cf immune receptor genes (Iida et al. 2015; Joosten et al. 1994; Luderer et al. 2002a; Mesarich et al. 2014; Westerink et al. 2004). To assess the level of allelic variation across genes encoding the HR-eliciting SSPs, each was amplified by PCR from 10 different $C$. fulvum strains (Supplementary Table S5), was sequenced, and was compared with the corresponding sequence from strain OWU. All nine SSP genes could be amplified by PCR from genomic DNA samples representing the 10 C. fulvum strains. Of the nine genes, four, namely Ecp9-1, Ecp10-1, Ecp13, and Ecp 15, exhibited no allelic variation between strains. For Ecp 8 and Ecp 16, allelic variation was observed; however, this variation did not result in a change of amino-acid sequence. More specifically, in six strains $(2.4,2.4 .5,2.5,2.9,4$, and 7320), Ecp 8 had a single synonymous CCC $\rightarrow$ CCT substitution at position 153 (underlined), while, in four strains (2.4, 2.4.5, 2.5, and 4), Ecpl6 had a trinucleotide insertion (CTT) at position 234 in an intron (Fig. 5). For each of the remaining three genes, a single nonsynonymous substitution was identified (underlined): a TTT $\rightarrow$ GTT (Phe119Val) change at position 355 in Ecpl1-1 of strain 2.9, a GGG $\rightarrow$ AGG (Gly124Arg) change at position 484 in Ecp12 of strains 2.9 and 7320, and an AAG $\rightarrow$ GAG (Lys148Glu) change at position 501 in Ecpl4-1 of strains 2.4, 2.4.5, 2.4.5.9.11 IPO, 2.4.9.11, 2.5, 2.9, and 4 (Fig. 5). A G $\rightarrow$ T mutation at position 386 of the Ecpl4-1 intron in strains 2.4, 2.4.5, 2.4.5.9.11 IPO, 2.4.9.11, 2.5 , and 4 , as well as a synonymous GGG $\rightarrow$ GGA substitution at position 452 in Ecp 14-1 of strains 2.4, 2.4.5, 2.4.5.9.11 IPO, 2.4.9.11, 2.5, 2.9, and 4 were also identified (Fig. 5). It is not yet known whether the nonsynonymous substitutions identified in Ecp11-1, Ecp12, and Ecp14-1 allow C. fulvum to overcome resistance mediated by the putative $C f$-Ecpl1-1, $C f$-Ecp12, and $C f$-Ecp14-1 immune receptor genes, respectively.

\section{DISCUSSION}

Leaf mold disease of tomato, caused by the fungal pathogen C. fulvum, is a re-emerging problem worldwide. This reemergence is due to the intensive year-round cultivation of resistant tomato cultivars, which have selected for natural strains of this fungus, capable of overcoming, for example, one or more of all cloned $\mathrm{Cf}$ immune receptor genes (Hubbeling 1978; Iida et al. 2015; Laterrot 1986; Li et al. 2015). To combat these strains, new $\mathrm{Cf}$ immune receptor genes need to be identified. Wild tomato is a rich source of resistance against C. fulvum (Kruijt et al. 2005; Laugé et al. 1998, 2000; Van der Hoorn et al. 2001b). In this study, an effectoromics approach (Domazakis et al. 2017; Du and Vleeshouwers 2014) based on apoplastic in planta-induced SSPs of C. fulvum was used to identify wild accessions of tomato carrying new $\mathrm{Cf}$ immune receptor genes.

As a starting point for this approach, proteomics and transcriptome sequencing were used to identify fungal SSPs most relevant to the $C$. fulvum-tomato interaction. Altogether, 70 apoplastic in planta-induced SSPs, made up of all 11 characterized SSP effectors of this fungus (Bolton et al. 2008; Joosten et al. 1994; Laugé et al. 2000; Luderer et al. 2002a; Mesarich et al. 2014; Van den Ackerveken et al. 1993; van Kan et al. 1991; Westerink et al. 2004), as well as two phialide proteins and 57 new extracellular proteins were identified in IWF samples from compatible $C$. fulvum-S. lycopersicum cv. H-Cf-0 interactions. Strikingly, all but eight of these SSPs are Cys-rich and possess an even number of Cys residues. Consistent with that shown for Avr4, Avr9, Ecp1, Ecp2-1, Ecp5, and Ecp6, it is likely that many of these Cys residues form intramolecular disulphide bonds required for stability and function in the protease-rich leaf apoplast of tomato (Joosten et al. 1997; Luderer et al. 2002b; Sánchez-Vallet et al. 2013; van den Burg et al. 2003; van den Hooven et al. 2001).

BLAST homology searches revealed that, in addition to Avr4 (CBM_14 domain, PF01607) (van den Burg et al. 2003), Ecp2-1 (Hce2 domain, PF14856) (Stergiopoulos et al. 2012), Ecp6 (three

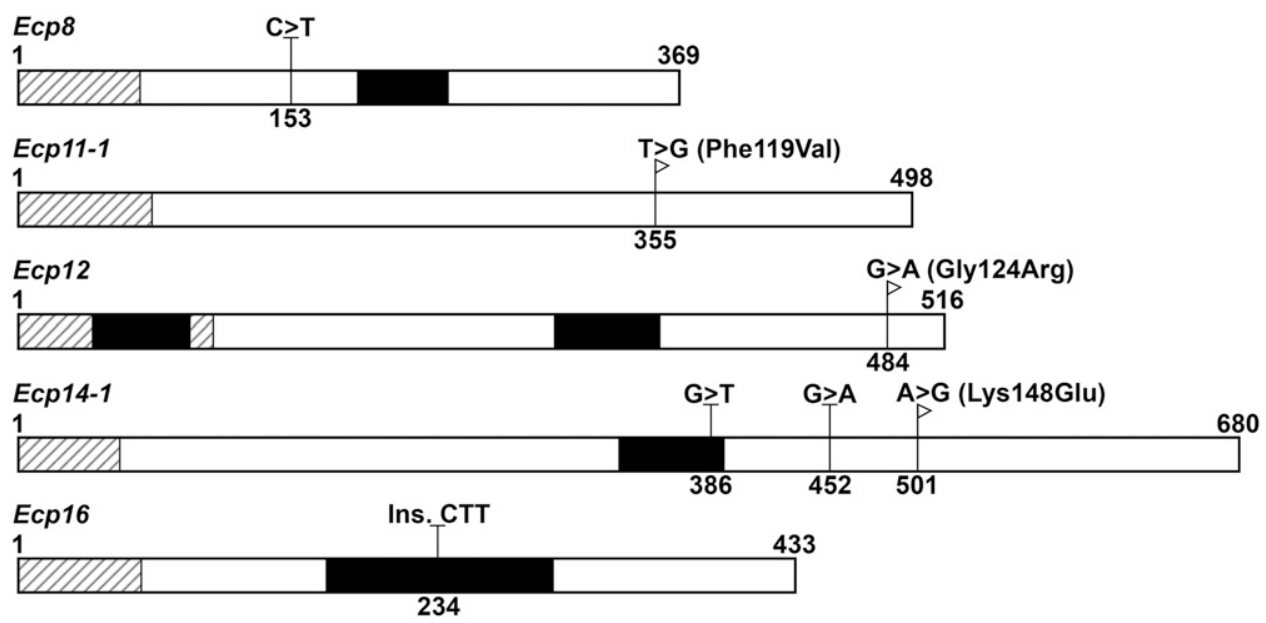

Fig. 5. Genes encoding a hypersensitive response-eliciting small secreted protein (SSP) exhibit limited allelic variation between strains of Cladosporium fulvum. Allelic variation was assessed across 10 distinct strains of $C$. fulvum and was compared with strain 0WU. Open reading frames (encoding each mature protein) and introns are shown as white and black boxes, respectively. Regions of each SSP gene predicted to encode an amino (N)-terminal signal peptide sequence are indicated by black diagonal lines. DNA modifications leading to nonsynonymous amino-acid substitutions are indicated by white flags. DNA modifications leading to synonymous amino-acid mutations or changes to intronic sequences are indicated by Ts. Numbers above each schematic represent the first and last nucleotide of each gene (i.e., of the ATG to STOP codons, respectively). Numbers on the bottom of each schematic represent the location of each DNA modification. 
LysM domains, PF01476) (Bolton et al. 2008), and CfPhiA-1 (phialide protein) (Bolton et al. 2008), five other in plantainduced SSPs, specifically CfPhiA-2, Ecp14-1, Ecp44, Ecp45, and Ecp50-1, possess a known functional domain or have homology to proteins with a characterized biological function. Of these, CfPhiA-2 has homology to CfPhiA-1 and other phialide proteins from Ascomycete fungi. To date, the best-characterized of these homologs is PhiA from Aspergillus nidulans, which localizes to the cell wall of phialides and conidia (Melin et al. 2003). PhiA plays an essential role in the development of phialides, which are sporogenous cells that produce and release conidia through a specialized apical budding process (Melin et al. 2003)

Ecp14-1 is a member of the hydrophobins, a class of surfaceactive proteins specific to fungi (Wessels 1994). Ecp14-1 is the twelfth hydrophobin and sixth class II hydrophobin to be identified from $C$. fulvum (de Wit et al. 2012; Nielsen et al. 2001; Segers et al. 1999; Spanu 1997). It is also the first hydrophobin to be identified from this fungus that is exclusively expressed in planta (Fig. 4). Hydrophobins are initially secreted in a soluble form but, then, spontaneously localize to hydrophilic-hydrophobic interfaces, where they assemble into insoluble, amphipathic layers (Sunde et al. 2017). Hydrophobins are typically found on the outer cell-wall surface of aerial hyphae, fruiting bodies, and spores, in which they reduce wettability or significantly decrease the surface tension of moist environments, allowing these structures to grow in the air (Wösten et al. 1999). Other roles related to surface perception, attachment to hydrophobic surfaces, and plant colonization have also been shown (Kim et al. 2005; Talbot et al. 1993, 1996). So far, only two C. fulvum hydrophobins, HCf-1 (class I) and HCf-6 (class II), have been functionally characterized. HCf-1 is required for efficient water-mediated dispersal of conidia (Whiteford and Spanu 2001), while HCf-6 is required for adhesion of hyphae to solid surfaces (Lacroix et al. 2008).

Ecp44 has a GPI-anchored superfamily domain (PF10342) but is not predicted to possess a GPI anchor modification site. Little functional information is available for secreted proteins with this domain. In the Basidiomycete fungus Lentinula edodes (shiitake mushroom), the PF10342 domain-containing protein Le.DRMIP, which also possesses a mitochondrial targeting signal peptide and transmembrane domain, interacts with the developmentally regulated mitogen-activated protein kinase Le.MAPK. Both proteins have been proposed to play a role in cell differentiation during fruiting body development (Szeto et al. 2007).

Ecp45 is a member of the cerato-platanins (PF07249), a class of proteins ubiquitous to filamentous fungi that adopts a double $\Psi \beta$-barrel fold similar to domain one of expansins (Chen et al. 2013; de Oliveira et al. 2011). Cerato-platanins are predominantly secreted, although several also localize to the cell wall of ascospores, conidia, and hyphae (Boddi et al. 2004; Pazzagli et al. 1999). Cerato-platanins bind chitin but not cellulose (Baccelli et al. 2014; de O. Barsottini et al. 2013; Frischmann et al. 2013), yet several members have expansin-like loosening activity on cellulosic materials in vitro (Baccelli et al. 2014; de O. Barsottini et al. 2013). It has thus been hypothesized that cerato-platanins function as expansins required for fungal cellwall remodeling and enlargement, possibly by disrupting noncovalent interactions between $\beta$-glucan or chitin molecules (de Oliveira et al. 2011). Epl1, a surface-active cerato-platanin from the biocontrol agent Trichoderma atroviride, self-assembles at the air-water interface to form protein films that increase the polarity of solutions and surfaces (Frischmann et al. 2013). This suggests an additional role for cerato-platanins in increasing the wettability of hyphae, enabling them to grow in aqueous environments, or in protecting them from desiccation (Frischmann et al. 2013). Other cerato-platanins likely function as effectors
(Jeong et al. 2007). Indeed, preliminary studies have suggested that MpCP5, a cerato-platanin from Moniliophthora perniciosa (witches' broom disease of cocoa) may, like Ecp6, perturb chitintriggered immunity (de O. Barsottini et al. 2013), while ceratoplatanins from Fusarium graminearum (cereal head blight disease) may, like Avr4, protect the fungal cell wall against hydrolysis by chitinases and $\beta$-1,3-glucanases (Quarantin et al. 2016). Some cerato-platanins also trigger a nonspecific HR upon recognition by corresponding host immune receptors (Frías et al. 2011, 2014). This, however, does not appear to be the case for Ecp45, which failed to trigger an HR in tomato.

Ecp50-1 contains an HsbA domain (PF12296), which was originally identified in the HsbA protein from Aspergillus oryzae (Ohtaki et al. 2006), a filamentous fungus commonly used in the fermentation industry. In culture, HsbA is secreted in the presence of the hydrophobic polymer polybutylene succinate-co-adipate (PBSA). HsbA binds PBSA and, in doing so, recruits CutL1, a polyesterase and cutinase, for its degradation (Ohtaki et al. 2006).

BLAST homology searches revealed that all other $C$. fulvum in planta-induced SSPs are novel or have homology to proteins of unknown function. Remarkably, 10 of these SSPs were consistently predicted to have structural homology to proteins present in the RCSB protein databank. Of these, Ecp20-1, Ecp20-2, and Ecp20-3 were predicted to be structurally homologous to Alt a 1 from A. alternata, which adopts a $\beta$-barrel fold unique to fungi (Chruszcz et al. 2012; De Vouge et al. 1996). Recent studies have shown that Alt a 1 is an effector protein with multiple roles in promoting host colonization. Initially, Alt a 1 localizes to the cytoplasm and cell wall of A. alternata spores (Garrido-Arandia et al. 2016b; Gómez-Casado et al. 2014). In humid settings, these spores then germinate, and, in environments with a pH range of between 5.0 and 6.5, Alt a 1 is released as a tetramer carrying a fungal methoxyflavonol ligand similar to the plant flavonol quercetin (Garrido-Arandia et al. 2016a and b). In the same $\mathrm{pH}$ range, which is typical of apoplastic environments, this complex breaks down, releasing Alt a 1 monomers and the flavonol ligand (Garrido-Arandia et al. 2016a and b). The Alt a 1 monomers then function as competitive inhibitors of extracellular plant defense proteins belonging to the pathogenesisrelated 5-thaumatin-like protein family (Gómez-Casado et al. 2014), while the flavonol ligand detoxifies reactive oxygen species (Garrido-Arandia et al. 2016b). Interestingly, homologs of Ecp20-1, Ecp20-2, and Ecp20-3 are encoded by the genome of D. septosporum (de Wit et al. 2012) and these genes are upregulated during the infection of pine (Bradshaw et al. 2016). This suggests that Ecp20-1, Ecp20-2, and Ecp20-3, together with Ecp2-1, Ecp6, Ecp14-1, and Ecp45, which are also in plantainduced SSPs of D. septosporum (Bradshaw et al. 2016; de Wit et al. 2012), are core effectors that play important roles in the virulence of both pathogens. These D. septosporum SSPs have been short-listed for future functional characterization (Hunziker et al. 2016).

Four of the nine in planta-induced SSPs, specifically Ecp4, Ecp7, Ecp29 (CTR), and Ecp30, were predicted to be structurally homologous to proteins with a $\beta / \gamma$-crystallin fold. Of these, Ecp4, Ecp7, and Ecp29 (CTR) were found to share a Cys spacing profile with MiAMP1, a plant antimicrobial protein with a $\beta / \gamma$-crystallin fold from nut kernels of M. integrifolia (Marcus et al. 1997; McManus et al. 1999). Purified MiAMP1 exhibits broad-spectrum inhibitory activity against several plant-pathogenic fungi, oomycetes, and gram-positive bacteria in vitro (Marcus et al. 1997). Although a specific mode of action has not yet been determined (Stephens et al. 2005), more functional information is available for Sp-AMP3, a homolog of MiAMP1 from the Scots pine Pinus sylvestris (Asiegbu et al. 2003; Sooriyaarachchi et al. 2011). Purified Sp-AMP3 protein has antifungal activity against the 
root-rotting Basidiomycete Heterobasidion annosum and, as part of this, causes morphological changes in the hyphae and spores of this fungus (Sooriyaarachchi et al. 2011). Carbohydratebinding assays revealed that Sp-AMP3 binds to both soluble and insoluble $\beta$-1,3-glucans but not to insoluble chitin or chitosan (Sooriyaarachchi et al. 2011). It is possible that, through this binding, Sp-AMP3 interferes with glucan assembly. This could then alter cell-wall structure, causing the above-mentioned morphological changes, or could compromise cell-wall integrity to cause cell lysis (Sooriyaarachchi et al. 2011).

The three remaining in planta-induced SSPs, specifically Ecp28-1, Ecp28-2, and Ecp28-3, were predicted to be structurally homologous to KP6, a killer toxin secreted by specific strains of the fungal corn smut pathogen $U$. maydis. These strains exhibit a "killer" phenotype, which is due to persistent infection by a KP6-producing double-stranded RNA totivirus, P6. Upon secretion, KP6 kills competing, uninfected strains of U. maydis (Allen et al. 2013b; Koltin and Day 1975). KP6 is translated as a single polypeptide but is processed into two subunits, KP6 $\alpha$ and KP6 $\beta$, by a kexin protease during passage through the ER-Golgi secretory pathway. Both subunits adopt a core $\alpha / \beta$-sandwich fold (Allen et al. 2013a; Li et al. 1999). KP6 functions only as a heterodimer, with both subunits required for cytotoxic activity (Peery et al. 1987). Assays in which sensitive $U$. maydis cells were treated with KP6 $\alpha$ or KP6 $\beta$ alone or with one subunit after another, but with a washing step in between, strongly suggest that $\mathrm{KP} 6 \alpha$ is responsible for targeting the cell, while KP6 $\beta$ is cytotoxic (Peery et al. 1987). The specific mode of action for KP6, however, remains unclear, although it is thought that KP6 $\alpha$ forms strong interactions with cell-wall carbohydrates or membrane-associated proteins of the target cell, with KP6 $\beta$ subsequently recruited to the plasma membrane or imported to an intracellular target to cause cell lysis (Allen et al. 2013a; Steinlauf et al. 1988). Interestingly, limited amino-acid sequence homology was identified between Ecp29 (NTR) and members of the Ecp28 family, suggesting that Ecp29 (NTR) also adopts a KP6-like fold. A putative kexin protease cleavage site is located between the NTR and CTR ( $\beta / \gamma$-crystallin-like domain) of Ecp 29 , implying that this protein undergoes similar posttranslational processing to KP6 upon passage through the ER-Golgi secretory pathway.

In total, $10 \%$ of the C. fulvum apoplastic in planta-induced SSPs are predicted to possess a domain typical of antimicrobial proteins. This raises the possibility that $C$. fulvum dedicates a significant proportion of its apoplastic secretome to functions associated with microbial antagonism, perhaps to outcompete other microbial organisms for nutrients and space in the apoplastic environment or to provide a form of self-defense (Rovenich et al. 2014). Of course, it remains possible that the predicted similarities in tertiary structure do not extend to biological function. Instead, these folds may be more common than previously thought, irrespective of whether they have evolved from an ancestral protein or by convergent evolution, providing solutions to typical problems faced at the hostile host-pathogen interface. For example, the above-mentioned folds may provide enhanced stability in protease-rich environments. Alternatively, they may provide a flexible molecular scaffold for either functional diversification, the evasion of recognition by corresponding host immune receptors, or both. Recently, the Avr effectors Avr1-CO39, AVR-Pia, and AvrPiz-t from the rice blast fungus Magnaporthe oryzae as well as the ToxB effector from Pyrenophora tritici-repentis were found to be structurally related (de Guillen et al. 2015). Structureinformed pattern searches carried out in the same study also revealed that several other effector candidates from Sordariomycete and Dothideomycete plant pathogens likely share this same fold. It has, thus, been hypothesized that "the enormous number of sequence-unrelated Ascomycete effectors may in fact belong to a restricted set of structurally conserved effector families" (de Guillen et al. 2015). Certainly, the predicted structural relationship between Alt a 1 and members of the Ecp20 family further supports this hypothesis.

Of the 70 apoplastic in planta-induced SSPs from $C$. fulvum, 41 were screened for recognition by wild tomato accessions, using an effectoromics approach based on the PVX transient expression system (Hammond-Kosack et al. 1995; Takken et al. 2000). Such an approach has been successful for the identification of plants carrying immune receptor genes active against other pathogens. For example, of 54 RXLR effectors from the oomycete potato late blight pathogen Phytophthora infestans, 31 were found to trigger an HR in one or more of 10 resistant wild Solanum accessions, with each accession recognizing between five and 24 effectors (Vleeshouwers et al. 2008). In the current study, nine $C$. fulvum SSPs were found to trigger an HR in one or more of 14 specific wild accessions of tomato. This suggests that nine new Avr effectors of this fungus as well as nine new corresponding $\mathrm{Cf}$ immune receptor genes have been uncovered. One of the recognized SSPs, Ecp11-1, is a homolog of AvrLm3, an Avr effector from Leptosphaeria maculans (Plissonneau et al. 2016). This suggests that both tomato and Brassica spp. carry an immune receptor capable of recognizing this class of effector.

Consistent with Ecp 1, Ecp2-1, Ecp4, and Ecp5 (Stergiopoulos et al. 2007), all genes encoding a new HR-eliciting SSP were found to exhibit limited allelic variation across strains collected from around the world. As has been suggested for Ecpl, Ecp2-1, Ecp4, and Ecp5 (Stergiopoulos et al. 2007), this limited allelic variation could reflect a lack of selection pressure imposed on the pathogen to overcome $\mathrm{Cf}$ immune receptor-mediated resistance, since, so far as we are aware, none of the putative corresponding $\mathrm{Cf}$ immune receptor genes have yet been deployed in commercial tomato cultivars. Alternatively, this lack of allelic variation could reflect selective constraints on the SSPs to maintain their protein sequences (i.e., to ensure full virulence of the pathogen). Of note, all genes encoding a new HR-eliciting SSP, except for Ecp 14-1, are associated with repetitive elements in the genome of C. fulvum OWU. It is, therefore, possible that homologous recombination between flanking repetitive elements could result in the deletion of these genes, as hypothesized for strains lacking the repeat-associated Avr effector genes Avr4E, Avr5, or Avr9 (Mesarich et al. 2014; van Kan et al. 1991; Westerink et al. 2004). Thus, to increase potential durability, new Cf immune receptor genes should be stacked in resistant tomato cultivars.

Two responding species of wild tomato used in our study, $S$. corneliomuelleri and $S$. peruvianum, are typically selfincompatible (Peralta and Spooner 2006). While Cf immune receptor genes present in self-compatible accessions can be easily introgressed into commercial and breeder's cultivars of S. lycopersicum by backcrossing, this is not possible for selfincompatible accessions. In cases of incompatibility, it may be possible to avoid the problems associated with barriers to genetic crossing through a more extensive screen of wild tomato germplasm to identify self-compatible species capable of recognizing the SSPs. This strategy has been successful for the identification of wild potato species that recognize the AVRblb1 Avr effector of Phythophthora infestans (Vleeshouwers et al. 2008). Using an effectoromics approach based on the PVX transient expression system, it was initially determined that the wild potato species Solanum bulbocastanum, which is not directly sexually compatible with the cultivated potato Solanum tuberosum, carries an immune receptor gene, RB/Rpi-blb1, corresponding to AVRblb1 (Vleeshouwers et al. 2008). As direct introgression of RB/Rpi-blbl from $S$. bulbocastanum to $S$. tuberosum is not possible, additional screening was carried out to identify wild potato accessions that are 
both sexually compatible with cultivated potato and that recognize AVRblb1. HR-associated recognition of AVRblb1 was quickly detected in the sexually compatible species Solanum stoloniferum, which was subsequently found to carry Rpi-stol, a functional homolog of RB/Rpi-blb1 (Vleeshouwers et al. 2008).

The finding that most new HR-eliciting SSPs have homologs in other plant-pathogenic fungi raises the possibility of crossspecies resistance. In support of this possibility, the Cf-4 immune receptor has been shown to recognize homologs of Avr4 from D. septosporum, P. fijiensis, and Pseudocercospora fuligena (black leaf mold disease of tomato) (de Wit et al. 2012; Kohler et al. 2016; Stergiopoulos et al. 2010), while the CfEcp2-1 immune receptor has been shown to recognize homologs of Ecp2-1 from D. septosporum and P. fijiensis (de Wit et al. 2012; Stergiopoulos et al. 2010). It must be pointed out, however, that the Cf-4 immune receptor does not recognize homologs of Avr4 from Cercospora apii, Cercospora beticola, and Cercospora nicotianae (leaf spot disease of celery, beet, and tobacco, respectively) (Mesarich et al. 2016; Stergiopoulos et al. 2010). It is clear that, to provide effective resistance in a recipient plant species, the product of any transferred $\mathrm{Cf}$ immune receptor gene must recognize an epitope (direct recognition) or virulence function (indirect recognition) conserved to both the corresponding C. fulvum effector and its homolog from the target fungal pathogen.

\section{Conclusions.}

In this study, proteomics and transcriptome sequencing were used to identify a set of 70 apoplastic in planta-induced SSPs from C. fulvum that is made up of all 11 characterized SSP effectors of this fungus as well as two phialide proteins and 57 new extracellular proteins. These SSPs provide new insights into how C. fulvum promotes colonization of the tomato leaf apoplast. Using an effectoromics approach, nine SSPs were found to be recognized by specific wild accessions of tomato. These accessions likely carry new $\mathrm{Cf}$ immune receptor genes available for incorporation into cultivated tomato.

\section{MATERIALS AND METHODS}

In this study, all kits and reagents were used, unless otherwise specified, in accordance with the manufacturer's instructions.

\section{Isolation of IWF from the leaf apoplast of $C$. fulvum-infected tomato.}

Four- to five-week-old H-Cf-0 tomato plants were inoculated with strains 0WU, 4, IPO 1979, or IPO 2559 of C. fulvum (compatible interactions). For this purpose, conidia preparation, inoculation, and growth conditions were identical to those described by Mesarich et al. (2014). At 10 to 17 dpi, IWF was harvested from tomato leaves visibly infected with C. fulvum, using a previously described protocol (de Wit and Spikman 1982; Joosten 2012). Leaf debris and fungal material were then removed by centrifugation at $12,000 \times g$ and $4^{\circ} \mathrm{C}$ for $20 \mathrm{~min}$, and the IWF samples stored at $-20^{\circ} \mathrm{C}$ until required.

\section{Preparation of IWF samples for LC-MS/MS analysis.}

Frozen IWF samples were thawed on ice, and any precipitant formed during the freeze-thaw process was removed by centrifugation at $12,000 \times g$ and $4^{\circ} \mathrm{C}$ for $20 \mathrm{~min}$. IWF samples were concentrated 3 to $300 \times$ by i) pressure filtration at $4^{\circ} \mathrm{C}$, using an Amicon 8400 series Stirred Cell Ultrafiltration Unit (EMD Millipore) fitted with an Ultracel regenerated cellulose PLAC 1-kDa nominal molecular weight limit (NMWL) ultrafiltration membrane disc (EMD Millipore), ii) centrifugation at 4,000 $\times g$ and $4{ }^{\circ} \mathrm{C}$ in a $3-\mathrm{kDa}$ NMWL Amicon Ultra- 15 centrifugal filter unit (EMD Millipore) or a Vivaspin $203-\mathrm{kDa}$ molecular weight cut-off polyethersulfone ultrafiltration device (GE Healthcare), or iii) sequential acetone precipitation, as described by May et al. (1996), with final resuspension in $1 \mathrm{ml}$ of distilled $\mathrm{H}_{2} \mathrm{O}$. Following concentration, IWF samples were transferred to 2-ml LoBind microcentrifuge tubes (Eppendorf) and were stored at $-20^{\circ} \mathrm{C}$ until required for further processing. When required, frozen IWF samples were thawed on ice and any precipitant formed during the freeze-thaw process was removed by centrifugation at $12,000 \times g$ and $4^{\circ} \mathrm{C}$ for $20 \mathrm{~min}$. A filter-aided sample preparation protocol (Lu et al. 2011) or an in-gel digestion protocol (Karimi Jashni et al. 2015), both based on trypsin digestion, were then used to prepare samples for LC-MS/MS analysis.

\section{LC-MS/MS analysis.}

IWF samples were analyzed by nano-scale (n)LC-MS/MS with a Proxeon EASY nLC system connected to a LTQOrbitrap XL mass spectrometer (Lu et al. 2011) at the Laboratory of Biochemistry, Wageningen University. LC-MS runs and associated MS/MS spectra were analyzed with the MaxQuant v1.3.0.5 suite (Cox and Mann 2008), with default settings applied to the integrated Andromeda peptide search engine (Cox et al. 2011), with one exception, i.e., extra variable modifications were set for the deamidation of Asn and Gln. MS/MS spectra were searched against one of four sequence databases. These were built from i) a collection of common contaminants including, for example, bovine serum albumin (BSA) (P02769, BSA precursor), trypsin (P00760, bovine), trypsin (P00761, porcine), keratin K22E (P35908, human), keratin K1C9 (P35527, human), keratin K2C1 (P04264, human), and keratin K1CI (P35527, human); ii) a six-frame translation of tomato (S. lycopersicum cv. H-Cf-0) genome sequence (Tomato Genome Consortium 2012); iii) the predicted protein catalog of C. fulvum 0WU (de Wit et al. 2012; Mesarich et al. 2014) as well as a six-frame translation of the most highly abundant de novoassembled in vitro and in planta RNA-Seq reads of this fungus (Mesarich et al. 2014); and iv) a six-frame translation of the repeat-masked $C$. fulvum 0 WU genome sequence (de Wit et al. 2012). The 'label-free quantification' and 'match between runs' (set to $2 \mathrm{~min}$ ) options were enabled. Deamidated peptides were 'allowed' to be used for protein quantification. All other quantification settings were kept at default. Filtering and further bioinformatic analysis of the MaxQuant/Andromeda workflow output and the analysis of abundances for the identified proteins were performed with the Perseus v1.3.0.4 module as part of the MaxQuant suite. Peptides and proteins with a false discovery rate of less than $1 \%$ as well as proteins with at least one peptide across two or more IWF samples or two or more independent peptides in a single IWF sample were considered as reliable identification. Reversed hits were deleted from the MaxQuant results table, as were tomato and contamination hits.

\section{Identification of apoplastic in planta-induced SSPs from C. fulvum.}

C. fulvum SSPs directed to the apoplastic environment via the classical, conventional secretory pathway (i.e., SSPs that possess an N-terminal signal peptide but lack a GPI anchor modification site, a transmembrane domain, or a putative C-terminal ER retention or retention-like signal) were targeted for identification in the protein set identified by LC-MS/MS analysis. The SignalP v3.0 (Dyrløv Bendtsen et al. 2004) and v4.1 (Petersen et al. 2011) servers were used for signal peptide prediction, while the big-PI Fungal Predictor (Eisenhaber et al. 2004) and TMHMM v2.0 (Krogh et al. 2001) servers were used for the prediction of GPI anchor modification sites and transmembrane domains, respectively. 
Pre-existing RNA-Seq transcriptome sequencing data (Mesarich et al. 2014) from a compatible in planta time course involving C. fulvum OWU and S. lycopersicum cv. H-Cf-0 (4, 8, and 12 dpi) as well as from strain 0WU grown in vitro in PDB or Gamborg B5 liquid media (4 dpi) were used to predict which of the SSPs identified by LC-MS/MS analysis are encoded by in plantainduced genes. Although these data lack biological replicates, they have been extensively validated through RT-qrtPCR experiments (Mesarich et al. 2014; this study). Paired-end RNASeq reads were remapped to the strain $0 \mathrm{WU}$ genome sequence (de Wit et al. 2012) with Bowtie v2-2.1.0 (Langmead and Salzberg 2012) and TopHat v2.0.12 (Kim et al. 2013), using a custom script. Transcript assembly and abundance estimations were then performed using Cufflinks v2.0.2 (Trapnell et al. 2010), with transcript abundance expressed as FPKM values. SSPs were deemed to be in planta-induced if they were encoded by genes that had a maximum in planta FPKM value of $\geq 50$ at 4 , 8 , or 12 dpi that exceeded their maximum in vitro FPKM value at 4 dpi by a factor of $\geq 1.5$. Gene exon-intron boundaries were confirmed using the same RNA-Seq data.

\section{General homology screening and alignments.}

BLASTp screens (Altschul et al. 1997) were used to identify the top homolog of each C. fulvum apoplastic SSP in NCBI and JGI databases (Grigoriev et al. 2012). Only those hits with an expect (E)-value of $<1 \mathrm{E}-02$ or a conserved Cys-spacing were considered. Iterative BLASTp screens (Stergiopoulos et al. 2012) were used till saturation to identify homologs of each HR-eliciting SSP in the NCBI and JGI databases (i.e., homologs were used to identify additional homologs in subsequent rounds of BLASTp). Only those hits with an E-value of $<1 \mathrm{E}-02$ and the same number of Cys residues as the query sequence were considered. For those proteins for which a homolog could not be identified in JGI, a tBLASTn screen was carried out against the genome collection with the same E-value cut-off. Homologous proteins were aligned using the Clustal Omega server (Sievers et al. 2011).

\section{Structural modeling.}

Three-dimensional protein structure prediction servers were used to infer possible structural relationships between apoplastic in planta-induced SSPs of $C$. fulvum and proteins with characterized tertiary structures in the RCSB protein databank (Berman et al. 2000). Only those SSPs with no homology to proteins present in NCBI or JGI databases or those with homology to hypothetical proteins of unknown function in these databases were investigated. The prediction servers employed were HHPred (Hildebrand et al. 2009; Söding et al. 2005), SPARKS-X (Yang et al. 2011), MUSTER (Wu and Zhang 2008), FFAS03/FFAS-3D (Jaroszewski et al. 2005; Xu et al. 2013), FUGUE v2.0 (Shi et al. 2001), RaptorX (Källberg et al. 2012), pGenTHREADER (Lobley et al. 2009), Phyre2 (Kelley et al. 2015), and I-TASSER (Zhang 2008). For each server, default settings were used. A consistency of hits across server outputs, rather than significance values, was used to evaluate potential structural homology. Structural modeling was done with MODELER (HHPred) (Webb and Sali 2002) and RaptorX and was visualized using PyMOL (DeLano 2002).

\section{Repeat identification.}

BLASTn was used to identify repetitive nucleotide sequences shared between the genome scaffolds harboring an SSP gene and the rest of the $C$. fulvum $0 \mathrm{WU}$ genome. Only those sequence repeats of $\geq 100$ nucleotides in length and sharing $\geq 80 \%$ identity with an E-value threshold of $1 \mathrm{E}-05$ were considered. The maximum total number of sequence alignments considered per scaffold was set to 5,000.

\section{Homology screening and expression profiling in Dothistroma septosporum.}

Reciprocal BLASTp and tBLASTn screens were used to identify homologs of the apoplastic SSPs from C. fulvum in the D. septosporum NZE10 protein catalog and genome (de Wit et al. 2012) in the JGI database, respectively, with only those hits possessing an E-value of $<1 \mathrm{E}-02$ considered. RNA-Seq data from D. septosporum NZE10 (Bradshaw et al. 2016) were used to determine which of the homologs are most relevant to the D. septosporum-Pinus radiata interaction. More specifically, transcript abundance data from one in vitro growth condition (fungal mycelia in Dothistroma liquid medium) and three in planta growth conditions (epiphytic/biotrophic [early], initial necrosis [mid], and mature sporulating lesion [late]), expressed as reads per million per kilobase (RPMK) values, were used. Genes deemed relevant to the interaction had to have a maximum in planta RNA-Seq RPMK value of $\geq 50$ at the early, mid, or late time point. Furthermore, this value had to exceed the gene in vitro RPMK value by a factor of at least 1.5.

\section{PVX-mediated transient expression assays.}

Tomato accessions were screened for their ability to recognize apoplastic SSPs through the elicitation of an HR, using the PVX-based transient expression system (Hammond-Kosack et al. 1995; Takken et al. 2000). For this purpose, the cDNA sequence encoding a mature SSP was fused downstream of the cDNA sequence encoding the $N$. tabacum PR1A signal peptide (i.e., for secretion into the apoplastic environment) and was cloned into the binary PVX vector pSfinx behind the Cauliflower mosaic virus $35 \mathrm{~S}$ promoter (Takken et al. 2000). These steps were carried out using protocols of Mesarich et al. (2014) (overlap extension PCR and restriction enzyme-mediated cloning) or Mesarich et al. (2016) (overlap extension PCR and Gateway cloning [Invitrogen]) with the primer pairs listed in Supplementary Table S6. Constructs were transformed into Agrobacterium tumefaciens GV3101 for agroinfection of tomato by electroporation, using the method of Takken et al. (2000). For localized transient expression assays in tomato, transformants were prepared, using the protocol described by Stergiopoulos et al. (2010) but with resuspension in a final volume of $0.5 \mathrm{ml}$ of MMA $(2 \% \mathrm{wt} / \mathrm{vol}$ sucrose, $0.5 \% \mathrm{wt} / \mathrm{vol}$ Murashige and Skoog salts without vitamins, $0.195 \% \mathrm{wt} / \mathrm{vol} \mathrm{MES}$ [pH 5.6], $200 \mu \mathrm{M}$ acetosyringone), and were inoculated into fully expanded leaves by localized wounding on each side of the main vein with a toothpick (Luderer et al. 2002a; Takken et al. 2000). For systemic transient expression assays, transformants were again prepared, using the method of Stergiopoulos et al. (2010) with final resuspension in MMA to an optical density at $600 \mathrm{~nm}$ of 1.0, and were infiltrated into both cotyledons of a seedling at 10 days postgermination with a 1-ml needleless syringe (Mesarich et al. 2014). The presence or absence of an HR was visually assessed at 10 days postwounding and 3 weeks postinfiltration for systemic and localized transient expression assays, respectively.

\section{Tomato infection assays.}

Tomato accessions were inoculated with $C$. fulvum 2.4.5.9.11 IPO, using the method described by Mesarich et al. (2014), with resistance or susceptibility to this strain visually assessed across three independent plants at $14 \mathrm{dpi}$.

\section{RT-qrtPCR gene expression analysis.}

Leaf samples from compatible $C$. fulvum $0 \mathrm{WU}-S$. lycopersicum cv. H-Cf-0 interactions at 4, 8, 12, and 16 dpi as well as fungal samples from C. fulvum 0WU PDB and Gamborg B5 liquid media cultures at 4 dpi were collected according to Mesarich et al. (2014) and were stored at $-80^{\circ} \mathrm{C}$. Total RNA extraction from each sample as well as subsequent cDNA synthesis was carried out according 
to the protocol of Griffiths et al. (2017). RT-qrtPCR experiments were performed on cDNA samples using the method described by Ökmen et al. (2013). The $C$. fulvum actin gene was targeted as a reference for normalization of gene expression, and results were analyzed according to the cycle threshold $\left(2^{-\Delta C t}\right)$ method (Livak and Schmittgen 2001). Results were the average of three biological replicates.

\section{Allelic variation analysis.}

C. fulvum strains were grown in PDB, with conidia preparation, $\mathrm{PDB}$ inoculation, and culture conditions identical to those described by Mesarich et al. (2014). Genomic DNA was extracted from each strain according to the method of van Kan et al. (1991). Genes targeted for an analysis of allelic variation were amplified from genomic DNA by PCR using the protocol and reagents described by Mesarich et al. (2014). PCR amplicons were purified using an illustra GFX PCR DNA and gel band purification kit (GE Healthcare) and were directly sequenced at Macrogen Inc. (Seoul, South Korea), using the same gene-specific primers employed for PCR amplification.

\section{ACKNOWLEDGMENTS}

We thank S. Williams (Australian National University, Canberra, Australia) for advice on protein structure prediction, A. Sim (Massey University, Palmerston North, New Zealand) for mapping RNA-Seq reads to the D. septosporum genome, S. Boeren (Wageningen University, The Netherlands) for performing LC-MS/MS experiments, and W. van Dooijeweert (Centre for Genetic Resources, The Netherlands) for providing tomato seed. Financial assistance for this research was provided by Wageningen University, the Royal Netherlands Academy of Arts and Sciences, European Research Area-Plant Genomics, the Centre for BioSystems Genomics (part of The Netherlands Genomics Initiative/Netherlands Organization for Scientific Research, project TD8-35), and the New Zealand Bio-Protection Research Centre. Financial assistance for C. Wang was provided by the Chinese Scholarship Council. The authors declare no conflicts of interest.

\section{LITERATURE CITED}

Allen, A., Chatt, E., and Smith, T. J. 2013a. The atomic structure of the virally encoded antifungal protein, KP6. J. Mol. Biol. 425:609-621.

Allen, A., Islamovic, E., Kaur, J., Gold, S., Shah, D., and Smith, T. J. 2013 b. The virally encoded killer proteins from Ustilago maydis. Fungal Biol. Rev. 26:166-173.

Altschul, S. F., Madden, T. L., Schäffer, A. A., Zhang, J., Zhang, Z., Miller, W., and Lipman, D. J. 1997. Gapped BLAST and PSI-BLAST: A new generation of protein database search programs. Nucleic Acids Res. 25:3389-3402.

Antuch, W., Güntert, P., and Wüthrich, K. 1996. Ancestral $\beta \gamma$-crystallin precursor structure in a yeast killer toxin. Nat. Struct. Biol. 3:662-665.

Asiegbu, F. O., Choi, W., Li, G., Nahalkova, J., and Dean, R. A. 2003. Isolation of a novel antimicrobial peptide gene (Sp-AMP) homologue from Pinus sylvestris (Scots pine) following infection with the root rot fungus Heterobasidion annosum. FEMS Microbiol. Lett. 228:27-31.

Baccelli, I., Luti, S., Bernardi, R., Scala, A., and Pazzagli, L. 2014. Ceratoplatanin shows expansin-like activity on cellulosic materials. Appl. Microbiol. Biotechnol. 98:175-184.

Berman, H. M., Westbrook, J., Feng, Z., Gilliland, G., Bhat, T. N., Weissig, H., Shindyalov, I. N., and Bourne, P. E. 2000. The protein data bank. Nucleic Acids Res. 28:235-242.

Boddi, S., Comparini, C., Calamassi, R., Pazzagli, L., Cappugi, G., and Scala, A. 2004. Cerato-platanin protein is located in the cell walls of ascospores, conidia and hyphae of Ceratocystis fimbriata f. sp. platani. FEMS Microbiol. Lett. 233:341-346.

Bolton, M. D., van Esse, H. P., Vossen, J. H., de Jonge, R., Stergiopoulos, I., Stulemeijer, I. J. E., van den Berg, G. C. M., Borrás-Hidalgo, O., Dekker, H. L., de Koster, C. G., de Wit, P. J. G. M., Joosten, M. H. A. J., and Thomma, B. P. H. J. 2008. The novel Cladosporium fulvum lysin motif effector Ecp6 is a virulence factor with orthologues in other fungal species. Mol. Microbiol. 69:119-136.

Bradshaw, R. E., Guo, Y., Sim, A. D., Kabir, M. S., Chettri, P., Ozturk, I. K., Hunziker, L., Ganley, R. J., and Cox, M. P. 2016. Genome-wide gene expression dynamics of the fungal pathogen Dothistroma septosporum throughout its infection cycle of the gymnosperm host Pinus radiata. Mol. Plant Pathol. 17:210-224
Chen, H., Kovalchuk, A., Keriö, S., and Asiegbu, F. O. 2013. Distribution and bioinformatic analysis of the cerato-platanin protein family in Dikarya. Mycologia 105:1479-1488.

Chruszcz, M., Chapman, M.D., Osinski, T., Solberg, R., Demas, M., Porebski, P.J., Majorek, K.A., Pomes, A., and Minor, W. 2012. Alternaria alternata allergen Alt a 1: A unique $\beta$-barrel protein dimer found exclusively in fungi. J. Allergy Clin. Immunol. 130:241-247.

Cook, D. E., Mesarich, C. H., and Thomma, B. P. 2015. Understanding plant immunity as a surveillance system to detect invasion. Annu. Rev. Phytopathol. 53:541-563.

Cooke, M. 1883. New American fungi. Grevillea 12:22-33.

Cox, J., and Mann, M. 2008. MaxQuant enables high peptide identification rates, individualized p.p.b.-range mass accuracies and proteome-wide protein quantification. Nat. Biotechnol. 26:1367-1372.

Cox, J., Neuhauser, N., Michalski, A., Scheltema, R. A., Olsen, J. V., and Mann, M. 2011. Andromeda: A peptide search engine integrated into the MaxQuant environment. J. Proteome Res. 10:1794-1805.

de Guillen, K., Ortiz-Vallejo, D., Gracy, J., Fournier, E., Kroj, T., and Padilla, A. 2015. Structure analysis uncovers a highly diverse but structurally conserved effector family in phytopathogenic fungi. PLoS Pathog. 11:e1005228.

de Jonge, R., van Esse, H. P., Kombrink, A., Shinya, T., Desaki, Y., Bours, R., van der Krol, S., Shibuya, N., Joosten, M. H. A. J., and Thomma, B. P. H. J. 2010. Conserved fungal LysM effector Ecp6 prevents chitintriggered immunity in plants. Science 329:953-955.

de O. Barsottini, M. R., de Oliveira, J. F., Adamoski, D., Teixeira, P. J., do Prado, P. F., Tiezzi, H. O., Sforça, M. L., Cassago, A., Portugal, R. V., de Oliveira, P. S., de M Zeri, A. C., Dias, S. M., Pereira, G. A., and Ambrosio, A. L. 2013. Functional diversification of cerato-platanins in Moniliophthora perniciosa as seen by differential expression and protein function specialization. Mol. Plant-Microbe Interact. 26:1281-1293.

de Oliveira, A. L., Gallo, M., Pazzagli, L., Benedetti, C. E., Cappugi, G., Scala, A., Pantera, B., Spisni, A., Pertinhez, T. A., and Cicero, D. O. 2011. The structure of the elicitor cerato-platanin (CP), the first member of the $\mathrm{CP}$ fungal protein family, reveals a double $\psi \beta$-barrel fold and carbohydrate binding. J. Biol. Chem. 286:17560-17568.

De Vouge, M. W., Thaker, A. J., Curran, I. H., Zhang, L., Muradia, G., Rode, H., and Vijay, H. M. 1996. Isolation and expression of a cDNA clone encoding an Alternaria alternata Alt a 1 subunit. Int. Arch. Allergy Immunol. 111:385-395.

de Wit, P. J. G. M., Joosten, M. H. A. J., Thomma, B. P. H. J., and Stergiopoulos, I. 2009. Gene for gene models and beyond: The Cladosporium fulvumtomato pathosystem. Pages 135-156 in: Plant Relationships. H. B. Deising, ed. Springer, Berlin.

de Wit, P. J. G. M., and Spikman, G. 1982. Evidence for the occurrence of race and cultivar-specific elicitors of necrosis in intercellular fluids of compatible interactions of Cladosporium fulvum and tomato. Physiol. Plant Pathol. 21:1-11.

de Wit, P. J. G. M., van der Burgt, A., Ökmen, B., Stergiopoulos, I., AbdElsalam, K. A., Aerts, A. L., Bahkali, A. H., Beenen, H. G., Chettri, P., Cox, M. P., Datema, E., de Vries, R. P., Dhillon, B., Ganley, A. R., Griffiths, S. A., Guo, Y., Hamelin, R. C., Henrissat, B., Kabir, M. S., Karimi Jashni, M., Kema, G., Klaubauf, S., Lapidus, A., Levasseur, A. Lindquist, E., Mehrabi, R., Ohm, R. A., Owen, T. J., Salamov, A., Schwelm, A., Schijlen, E., Sun, H., van den Burg, H. A., van Ham, R. C. H. J., Zhang, S., Goodwin, S. B., Grigoriev, I. V., Collemare, J., and Bradshaw, R. E. 2012. The genomes of the fungal plant pathogens Cladosporium fulvum and Dothistroma septosporum reveal adaptation to different hosts and lifestyles but also signatures of common ancestry. PLoS Genet. 8:e1003088.

DeLano, W. L. 2002. The PyMOL molecular graphics system. DeLano Scientific, Palo Alto, CA, U.S.A.

Deng, C. H., Plummer, K. M., Jones, D. A. B., Mesarich, C. H., Shiller, J., Taranto, A. P., Robinson, A. J., Kastner, P., Hall, N. E., Templeton, M. D., and Bowen, J. K. 2017. Comparative analysis of the predicted secretomes of Rosaceae scab pathogens Venturia inaequalis and V. pirina reveals expanded effector families and putative determinants of hos range. BMC Genomics 18:339.

Dixon, M. S., Hatzixanthis, K., Jones, D. A., Harrison, K., and Jones, J. D. G. 1998. The tomato $C f-5$ disease resistance gene and six homologs show pronounced allelic variation in leucine-rich repeat copy number. Plant Cell 10:1915-1925.

Dixon, M. S., Jones, D. A., Keddie, J. S., Thomas, C. M., Harrison, K., and Jones, J. D. G. 1996. The tomato $C f$-2 disease resistance locus comprises two functional genes encoding leucine-rich repeat proteins. Cell 84: 451-459.

Domazakis, E., Lin, X., Aguilera-Galvez, C., Wouters, D., Bijsterbosch, G., Wolters, P. J., and Vleeshouwers, V. G. A. A. 2017. Effectoromics-based 
identification of cell surface receptors in potato. Pages 337-353 in: Plant Pattern Recognition Receptors: Methods and Protocols. L. Shan and P.He, eds. Springer, New York.

Du, J., and Vleeshouwers, V. G. A. A. 2014. The do's and don'ts of effectoromics. Pages 257-268 in: Plant-Pathogen Interactions: Methods and Protocols. P. Birch, T. J. Jones, and I. B. J. Bos, eds. Humana Press, Totowa, NJ.

Dyrløv Bendtsen, J. D., Nielsen, H., von Heijne, G., and Brunak, S. 2004 Improved prediction of signal peptides: SignalP 3.0. J. Mol. Biol. 340: 783-795.

Eisenhaber, B., Schneider, G., Wildpaner, M., and Eisenhaber, F. 2004. A sensitive predictor for potential GPI lipid modification sites in fungal protein sequences and its application to genome-wide studies for Aspergillus nidulans, Candida albicans, Neurospora crassa, Saccharomyces cerevisiae and Schizosaccharomyces pombe. J. Mol. Biol 337:243-253

Frías, M., Brito, N., González, M., and González, C. 2014. The phytotoxic activity of the cerato-platanin BcSpl1 resides in a two-peptide motif on the protein surface. Mol. Plant Pathol. 15:342-351.

Frías, M., González, C., and Brito, N. 2011. BcSpl1, a cerato-platanin family protein, contributes to Botrytis cinerea virulence and elicits the hypersensitive response in the host. New Phytol. 192:483-495.

Frischmann, A., Neudl, S., Gaderer, R., Bonazza, K., Zach, S., Gruber, S. Spadiut, O., Friedbacher, G., Grothe, H., and Seidl-Seiboth, V. 2013. Self-assembly at air/water interfaces and carbohydrate binding properties of the small secreted protein EPL1 from the fungus Trichoderma atroviride. J. Biol. Chem. 288:4278-4287.

Garrido-Arandia, M., Bretones, J., Gómez-Casado, C., Cubells, N., DíazPerales, A., and Pacios, L. F. 2016a. Computational study of pH-dependent oligomerization and ligand binding in Alt a 1, a highly allergenic protein with a unique fold. J. Comput. Aided Mol. Des. 30:365-379.

Garrido-Arandia, M., Silva-Navas, J., Ramírez-Castillejo, C., CubellsBaeza, N., Gómez-Casado, C., Barber, D., Pozo, J. C., Melendi, P. G. Pacios, L. F., and Díaz-Perales, A. 2016b. Characterisation of a flavonoid ligand of the fungal protein Alt a 1. Sci. Rep. 6:33468.

Gómez-Casado, C., Murua-García, A., Garrido-Arandia, M., GonzálezMelendi, P., Sánchez-Monge, R., Barber, D., Pacios, L. F., and DíazPerales, A. 2014. Alt a 1 from Alternaria interacts with PR5 thaumatin-like proteins. FEBS Lett. 588:1501-1508.

Griffiths, S., Mesarich, C. H., Overdijk, E., Saccomanno, B., de Wit, P. J. G. M., and Collemare, J. 2017. Down-regulation of cladofulvin biosynthesis is required for biotrophic growth of Cladosporium fulvum on tomato. Mol. Plant Pathol. Published online. doi:10.1111/mpp.12527

Grigoriev, I. V., Nordberg, H., Shabalov, I., Aerts, A., Cantor, M., Goodstein, D., Kuo, A., Minovitsky, S., Nikitin, R., Ohm, R. A., Otillar, R., Poliakov, A., Ratnere, I., Riley, R., Smirnova, T., Rokhsar, D., and Dubchak, I. 2012. The genome portal of the Department of Energy Joint Genome Institute. Nucleic Acids Res. 40:D26-D32.

Hammond-Kosack, K. E., Staskawicz, B. J., Jones, J. D. G., and Baulcombe, D. C. 1995. Functional expression of a fungal avirulence gene from a modified Potato virus X genome. Mol. Plant-Microbe Interact. 8:181-185.

Heath, M. C. 2000. Hypersensitive response-related death. Pages 77-90 in Programmed Cell Death in Higher Plants. Springer, New York.

Hildebrand, A., Remmert, M., Biegert, A., and Söding, J. 2009. Fast and accurate automatic structure prediction with HHpred. Proteins 77 (Suppl 9):128-132

Hubbeling, N. 1978. Breakdown of resistance of the Cf5 gene in tomato by another new race of Fulvia fulva. Meded. Fac. Landbouwwet. Rijksuniv. Gent 43:891-894.

Hunziker, L., Mesarich, C. H., McDougal, R. L., and Bradshaw, R. E. 2016. Effector identification in the pine pathogen Dothistroma septosporum. N. Z. Plant Protect-SE 69:94-98.

Iida, Y., van 't Hof, P., Beenen, H., Mesarich, C., Kubota, M., Stergiopoulos, I., Mehrabi, R., Notsu, A., Fujiwara, K., Bahkali, A., Abd-Elsalam, K., Collemare, J., and de Wit, P. J. G. M. 2015. Novel mutations detected in avirulence genes overcoming tomato $C f$ resistance genes in isolates of a Japanese population of Cladosporium fulvum. PLoS One 10:e0123271.

Jaroszewski, L., Rychlewski, L., Li, Z., Li, W., and Godzik, A. 2005. FFAS03: A server for profile-profile sequence alignments. Nucleic Acids Res. 33:W284-W288.

Karimi Jashni, M. K., Dols, I. H. M., Iida, Y., Boeren, S., Beenen, H. G., Mehrabi, R., Collemare, J., and de Wit, P. J. G. M. 2015. Synergistic action of a metalloprotease and a serine protease from Fusarium oxysporum f. sp. lycopersici cleaves chitin-binding tomato chitinases, reduces their antifungal activity, and enhances fungal virulence. Mol Plant-Microbe Interact. 28:996-1008.
Jenkins, J. 1948. The origin of the cultivated tomato. Econ. Bot. 2:379-392. Jeong, J. S., Mitchell, T. K., and Dean, R. A. 2007. The Magnaporthe grisea snodprot 1 homolog, MSP1, is required for virulence. FEMS Microbiol. Lett. 273:157-165.

Jones, D. A., Thomas, C. M., Hammond-Kosack, K. E., Balint-Kurti, P. J., and Jones, J. D. 1994. Isolation of the tomato $C f-9$ gene for resistance to Cladosporium fulvum by transposon tagging. Science 266:789-793.

Joosten, M. H., Vogelsang, R., Cozijnsen, T. J., Verberne, M. C., and De Wit, P. J. 1997. The biotrophic fungus Cladosporium fulvum circumvents Cf-4-mediated resistance by producing unstable AVR4 elicitors. Plant Cell 9:367-379.

Joosten, M. H. A. J. 2012. Isolation of apoplastic fluid from leaf tissue by the vacuum infiltration-centrifugation technique. Pages 603-610 in Plant Fungal Pathogens. M. D. Bolton and B. P. H. J. Thomma, eds Humana Press, New York.

Joosten, M. H. A. J., Cozijnsen, T. J., and De Wit, P. J. G. M. 1994. Host resistance to a fungal tomato pathogen lost by a single base-pair change in an avirulence gene. Nature 367:384-386.

Källberg, M., Wang, H., Wang, S., Peng, J., Wang, Z., Lu, H., and Xu, J. 2012. Template-based protein structure modeling using the RaptorX web server. Nat. Protoc. 7:1511-1522.

Kelley, L. A., Mezulis, S., Yates, C. M., Wass, M. N., and Sternberg, M. J. E. 2015. The Phyre2 web portal for protein modeling, prediction and analysis. Nat. Protoc. 10:845-858.

Kerr, E. A., and Bailey, D. L. 1964. Resistance to Cladosporium fulvum Cke. obtained from wild species of tomato. Can. J. Bot. 42:1541-1554.

Kerr, E. A., Patrick, Z. A., and Bailey, D. L. 1971. Resistance in tomato species to new races of leaf mold (Cladosporium fulvum Cke.). Hortic. Res. 11:84-92

Kim, D., Pertea, G., Trapnell, C., Pimentel, H., Kelley, R., and Salzberg, S. L. 2013. TopHat2: Accurate alignment of transcriptomes in the presence of insertions, deletions and gene fusions. Genome Biol. 14:R36.

Kim, S., Ahn, I.-P., Rho, H.-S., and Lee, Y.-H. 2005. MHP1, a Magnaporthe grisea hydrophobin gene, is required for fungal development and plant colonization. Mol. Microbiol. 57:1224-1237.

Kohler, A. C., Chen, L.-H., Hurlburt, N., Salvucci, A., Schwessinger, B., Fisher, A. J., and Stergiopoulos, I. 2016. Structural analysis of an Avr4 effector ortholog offers insight into chitin binding and recognition by the Cf-4 receptor. Plant Cell 28:1945-1965.

Koltin, Y., and Day, P. R. 1975. Specificity of Ustilago maydis killer proteins. Appl. Microbiol. 30:694-696.

Krogh, A., Larsson, B., von Heijne, G., and Sonnhammer, E. L. 2001. Predicting transmembrane protein topology with a hidden Markov model: Application to complete genomes. J. Mol. Biol. 305:567-580.

Krüger, J., Thomas, C. M., Golstein, C., Dixon, M. S., Smoker, M., Tang, S., Mulder, L., and Jones, J. D. 2002. A tomato cysteine protease required for $C f$-2-dependent disease resistance and suppression of autonecrosis. Science 296:744-747.

Kruijt, M., Kip, D. J., Joosten, M. H., Brandwagt, B. F., and de Wit, P. J. 2005. The $C f-4$ and $C f-9$ resistance genes against Cladosporium fulvum are conserved in wild tomato species. Mol. Plant-Microbe Interact. 18:1011-1021.

Lacroix, H., Whiteford, J. R., and Spanu, P. D. 2008. Localization of Cladosporium fulvum hydrophobins reveals a role for $\mathrm{HCf}-6$ in adhesion. FEMS Microbiol. Lett. 286:136-144.

Langmead, B., and Salzberg, S. L. 2012. Fast gapped-read alignment with Bowtie 2. Nat. Methods 9:357-359.

Laterrot, H. 1986. Race 2.5.9, a new race of Cladosporium fulvum (Fulvia fulva) and sources of resistance in tomato. Neth. J. Plant Pathol. 92:305-307.

Laugé, R., Goodwin, P. H., de Wit, P. J. G. M., and Joosten, M. H. A. J. 2000. Specific HR-associated recognition of secreted proteins from Cladosporium fulvum occurs in both host and non-host plants. Plant J. 23:735-745.

Laugé, R., Joosten, M. H., Haanstra, J. P., Goodwin, P. H., Lindhout, P., and De Wit, P. J. 1998. Successful search for a resistance gene in tomato targeted against a virulence factor of a fungal pathogen. Proc. Natl. Acad. Sci. U.S.A. 95:9014-9018.

Laugé, R., Joosten, M. H. A. J., van den Ackerveken, G. F. J. M., van den Broek, H. W. J., and de Wit, P. J. G. M. 1997. The in planta-produced extracellular proteins ECP1 and ECP2 of Cladosporium fulvum are virulence factors. Mol. Plant-Microbe Interact. 10:725-734.

Li, N., Erman, M., Pangborn, W., Duax, W. L., Park, C. M., Bruenn, J., and Ghosh, D. 1999. Structure of Ustilago maydis killer toxin KP6 alpha-subunit. A multimeric assembly with a central pore. J. Biol. Chem. 274:20425-20431.

Li, S., Zhao, T., Li, H., Xu, X., and Li, J. 2015. First report of races 2.5 and 2.4.5 of Cladosporium fulvum (syn. Passalora fulva), causal fungus of tomato leaf mold disease in China. J. Gen. Plant Pathol. 81:162-165.

Livak, K. J., and Schmittgen, T. D. 2001. Analysis of relative gene expression data using real-time quantitative PCR and the $2^{(-\Delta C(T)}$ method. Methods 25:402-408. 
Lobley, A., Sadowski, M. I., and Jones, D. T. 2009. pGenTHREADER and pDomTHREADER: New methods for improved protein fold recognition and superfamily discrimination. Bioinformatics 25:1761-1767.

Lu, J., Boeren, S., de Vries, S. C., van Valenberg, H. J., Vervoort, J., and Hettinga, K. 2011. Filter-aided sample preparation with dimethyl labeling to identify and quantify milk fat globule membrane proteins. J. Proteomics 75:34-43.

Luderer, R., De Kock, M. J., Dees, R. H., De Wit, P. J., and Joosten, M. H. 2002b. Functional analysis of cysteine residues of ECP elicitor proteins of the fungal tomato pathogen Cladosporium fulvum. Mol. Plant Pathol. 3:91-95.

Luderer, R., Takken, F. L. W., de Wit, P. J. G. M., and Joosten, M. H. A. J. 2002a. Cladosporium fulvum overcomes $C f$-2-mediated resistance by producing truncated AVR2 elicitor proteins. Mol. Microbiol. 45: 875-884.

Marcus, J. P., Goulter, K. C., Green, J. L., Harrison, S. J., and Manners, J. M. 1997. Purification, characterisation and cDNA cloning of an antimicrobial peptide from Macadamia integrifolia. Eur. J. Biochem. 244:743-749.

May, M. J., Hammond-Kosack, K. E., and Jones, J. 1996. Involvement of reactive oxygen species, glutathione metabolism, and lipid peroxidation in the $C f$-gene-dependent defense response of tomato cotyledons induced by race-specific elicitors of Cladosporium fulvum. Plant Physiol. 110:1367-1379.

McManus, A. M., Nielsen, K. J., Marcus, J. P., Harrison, S. J., Green, J. L., Manners, J. M., and Craik, D. J. 1999. MiAMP1, a novel protein from Macadamia integrifolia adopts a Greek key $\beta$-barrel fold unique amongst plant antimicrobial proteins. J. Mol. Biol. 293: 629-638

Melin, P., Schnürer, J., and Wagner, E. G. 2003. Characterization of phiA, a gene essential for phialide development in Aspergillus nidulans. Fungal Genet. Biol. 40:234-241.

Mesarich, C. H., Bowen, J. K., Hamiaux, C., and Templeton, M. D. 2015. Repeat-containing protein effectors of plant-associated organisms. Front. Plant Sci. 6:872.

Mesarich, C. H., Griffiths, S. A., van der Burgt, A., Ökmen, B., Beenen, H. G., Etalo, D. W., Joosten, M. H. A. J., and de Wit, P. J. G. M. 2014 Transcriptome sequencing uncovers the Avr5 avirulence gene of the tomato leaf mold pathogen Cladosporium fulvum. Mol. Plant-Microbe Interact. 27:846-857.

Mesarich, C. H., Stergiopoulos, I., Beenen, H. G., Cordovez, V., Guo, Y., Karimi Jashni, M., Bradshaw, R. E., and de Wit, P. J. G. M. 2016. A conserved proline residue in Dothideomycete Avr4 effector proteins is required to trigger a Cf-4-dependent hypersensitive response. Mol. Plant Pathol. 17:84-95.

Nielsen, P. S., Clark, A. J., Oliver, R. P., Huber, M., and Spanu, P. D. 2001. HCf-6, a novel class II hydrophobin from Cladosporium fulvum. Microbiol. Res. 156:59-63.

Ohtaki, S., Maeda, H., Takahashi, T., Yamagata, Y., Hasegawa, F., Gomi, K., Nakajima, T., and Abe, K. 2006. Novel hydrophobic surface binding protein, HsbA, produced by Aspergillus oryzae. Appl. Environ. Microbiol. 72:2407-2413

Ökmen, B., Etalo, D. W., Joosten, M. H. A. J., Bouwmeester, H. J., de Vos, R. C. H., Collemare, J., and de Wit, P. J. G. M. 2013. Detoxification of $\alpha$-tomatine by Cladosporium fulvum is required for full virulence on tomato. New Phytol. 198:1203-1214.

Panter, S. N., Hammond-Kosack, K. E., Harrison, K., Jones, J. D. G., and Jones, D. A. 2002. Developmental control of promoter activity is not responsible for mature onset of $C f-9 B$-mediated resistance to leaf mold in tomato. Mol. Plant-Microbe Interact. 15:1099-1107.

Pazzagli, L., Cappugi, G., Manao, G., Camici, G., Santini, A., and Scala, A. 1999. Purification, characterization, and amino acid sequence of ceratoplatanin, a new phytotoxic protein from Ceratocystis fimbriata f. sp. platani. J. Biol. Chem. 274:24959-24964.

Peery, T., Shabat-Brand, T., Steinlauf, R., Koltin, Y., and Bruenn, J. 1987. Virus-encoded toxin of Ustilago maydis: Two polypeptides are essential for activity. Mol. Cell. Biol. 7:470-477.

Peralta, I. E., and Spooner, D. M. 2006. History, origin and early cultivation of tomato (Solanaceae). Pages 1-27 in: Genetic Improvement of Solanaceous Crops Vol. 2. A. K. Matto, ed. Taylor \& Francis Group, Boca Raton, FL, U.S.A.

Petersen, T. N., Brunak, S., von Heijne, G., and Nielsen, H. 2011. SignalP 4.0: Discriminating signal peptides from transmembrane regions. Nat. Methods 8:785-786.

Plissonneau, C., Daverdin, G., Ollivier, B., Blaise, F., Degrave, A., Fudal, I., Rouxel, T., and Balesdent, M. H. 2016. A game of hide and seek between avirulence genes AvrLm4-7 and AvrLm3 in Leptosphaeria maculans. New Phytol. 209:1613-1624.
Quarantin, A., Glasenapp, A., Schäfer, W., Favaron, F., and Sella, L. 2016. Involvement of the Fusarium graminearum cerato-platanin proteins in fungal growth and plant infection. Plant Physiol. Biochem. 109: 220-229.

Rooney, H. C., Van't Klooster, J. W., van der Hoorn, R. A., Joosten, M. H., Jones, J. D., and de Wit, P. J. 2005. Cladosporium Avr2 inhibits tomato Rcr3 protease required for $C f$-2-dependent disease resistance. Science 308:1783-1786.

Rovenich, H., Boshoven, J. C., and Thomma, B. P. 2014. Filamentous pathogen effector functions: Of pathogens, hosts and microbiomes. Curr. Opin. Plant Biol. 20:96-103.

Sánchez-Vallet, A., Saleem-Batcha, R., Kombrink, A., Hansen, G., Valkenburg, D. J., Thomma, B. P., and Mesters, J. R. 2013. Fungal effector Ecp6 outcompetes host immune receptor for chitin binding through intrachain LysM dimerization. eLife 2:e00790.

Seear, P. J., and Dixon, M. S. 2003. Variable leucine-rich repeats of tomato disease resistance genes $C f-2$ and $C f-5$ determine specificity. Mol. Plant Pathol. 4:199-202.

Segers, G. C., Hamada, W., Oliver, R. P., and Spanu, P. D. 1999. Isolation and characterisation of five different hydrophobin-encoding cDNAs from the fungal tomato pathogen Cladosporium fulvum. Mol. Gen. Genet. 261:644-652.

Shabab, M., Shindo, T., Gu, C., Kaschani, F., Pansuriya, T., Chintha, R., Harzen, A., Colby, T., Kamoun, S., and van der Hoorn, R. A. 2008. Fungal effector protein AVR2 targets diversifying defense-related cys proteases of tomato. Plant Cell 20:1169-1183.

Shi, J., Blundell, T. L., and Mizuguchi, K. 2001. FUGUE: Sequencestructure homology recognition using environment-specific substitution tables and structure-dependent gap penalties. J. Mol. Biol. 310: 243-257.

Sievers, F., Wilm, A., Dineen, D., Gibson, T. J., Karplus, K., Li, W., Lopez, R., McWilliam, H., Remmert, M., Söding, J., Thompson, J. D., and Higgins, D. G. 2011. Fast, scalable generation of high-quality protein multiple sequence alignments using Clustal Omega. Mol. Syst. Biol. 7:539.

Söding, J., Biegert, A., and Lupas, A. N. 2005. The HHpred interactive server for protein homology detection and structure prediction. Nucleic Acids Res. 33:W244-W248.

Sooriyaarachchi, S., Jaber, E., Covarrubias, A. S., Ubhayasekera, W., Asiegbu, F. O., and Mowbray, S. L. 2011. Expression and $\beta$-glucan binding properties of Scots pine (Pinus sylvestris L.) antimicrobial protein (Sp-AMP). Plant Mol. Biol. 77:33-45.

Spanu, P. 1997. HCF-1, a hydrophobin from the tomato pathogen Cladosporium fulvum. Gene 193:89-96.

Steinlauf, R., Peery, T., Koltin, Y., and Bruenn, J. 1988. The Ustilago maydis virus-encoded toxin-Effect of KP6 on sensitive cells and spheroplasts. Exp. Mycol. 12:264-274

Stephens, C., Kazan, K., Goulter, K. C., Maclean, D. J., and Manners, J. M. 2005. The mode of action of the plant antimicrobial peptide MiAMP1 differs from that of its structural homologue, the yeast killer toxin WmKT. FEMS Microbiol. Lett. 243:205-210.

Stergiopoulos, I., De Kock, M. J. D., Lindhout, P., and De Wit, P. J. G. M. 2007. Allelic variation in the effector genes of the tomato pathogen Cladosporium fulvum reveals different modes of adaptive evolution. Mol. Plant-Microbe Interact. 20:1271-1283.

Stergiopoulos, I., Kourmpetis, Y. A. I., Slot, J. C., Bakker, F. T., De Wit, P. J. G. M., and Rokas, A. 2012. In silico characterization and molecular evolutionary analysis of a novel superfamily of fungal effector proteins. Mol. Biol. Evol. 29:3371-3384.

Stergiopoulos, I., van den Burg, H. A., Ökmen, B., Beenen, H. G., van Liere, S., Kema, G. H. J., and de Wit, P. J. G. M. 2010. Tomato C resistance proteins mediate recognition of cognate homologous effectors from fungi pathogenic on dicots and monocots. Proc. Natl. Acad. Sci. U.S.A. 107:7610-7615.

Sunde, M., Pham, C. L. L., and Kwan, A. H. 2017. Molecular characteristics and biological functions of surface-active and surfactant proteins. Annu. Rev. Biochem. 86:585-608.

Szeto, C. Y., Leung, G. S., and Kwan, H. S. 2007. Le.MAPK and its interacting partner, Le.DRMIP, in fruiting body development in Lentinula edodes. Gene 393:87-93.

Takken, F. L., Luderer, R., Gabriëls, S. H., Westerink, N., Lu, R., de Wit, P. J., and Joosten, M. H. 2000. A functional cloning strategy, based on a binary PVX-expression vector, to isolate HR-inducing cDNAs of plant pathogens. Plant J. 24:275-283.

Takken, F. L. W., Thomas, C. M., Joosten, M. H. A. J., Golstein, C., Westerink, N., Hille, J., Nijkamp, H. J. J., De Wit, P. J., and Jones, J. D. G. 1999. A second gene at the tomato $C f-4$ locus confers resistance to cladosporium fulvum through recognition of a novel avirulence determinant. Plant J. 20:279-288. 
Talbot, N. J., Ebbole, D. J., and Hamer, J. E. 1993. Identification and characterization of $M P G 1$, a gene involved in pathogenicity from the rice blast fungus Magnaporthe grisea. Plant Cell 5:1575-1590.

Talbot, N. J., Kershaw, M. J., Wakley, G. E., De Vries, O., Wessels, J., and Hamer, J. E. 1996. MPG1 encodes a fungal hydrophobin involved in surface interactions during infection-related development of Magnaporthe grisea. Plant Cell 8:985-999.

Thomas, C. M., Jones, D. A., Parniske, M., Harrison, K., Balint-Kurti, P. J., Hatzixanthis, K., and Jones, J. D. 1997. Characterization of the tomato $C f-4$ gene for resistance to Cladosporium fulvum identifies sequences that determine recognitional specificity in Cf-4 and Cf-9. Plant Cell 9: 2209-2224.

Thomma, B. P., Nürnberger, T., and Joosten, M. H. 2011. Of PAMPs and effectors: The blurred PTI-ETI dichotomy. Plant Cell 23:4-15.

Thomma, B. P. H. J., van Esse, H. P., Crous, P.W., and de Wit, P. J. G. M 2005. Cladosporium fulvum (syn. Passalora fulva), a highly specialized plant pathogen as a model for functional studies on plant pathogenic Mycosphaerellaceae. Mol. Plant Pathol. 6:379-393.

Tigchelaar, E. C. 1984. Collections of isogenic tomato stocks. Rep. Tomato Genet. Coop. 34:55-57.

Tomato Genome Consortium. 2012. The tomato genome sequence provides insights into fleshy fruit evolution. Nature 485:635-641.

Trapnell, C., Williams, B. A., Pertea, G., Mortazavi, A., Kwan, G., van Baren, M. J., Salzberg, S. L., Wold, B. J., and Pachter, L. 2010. Transcript assembly and quantification by RNA-Seq reveals unannotated transcripts and isoform switching during cell differentiation. Nat. Biotechnol. 28:511-515.

Van den Ackerveken, G. F., Van Kan, J. A., Joosten, M. H., Muisers, J. M., Verbakel, H. M., and De Wit, P. J. 1993. Characterization of two putative pathogenicity genes of the fungal tomato pathogen Cladosporium fulvum. Mol. Plant-Microbe Interact. 6:210-215.

van den Burg, H. A., Harrison, S. J., Joosten, M. H., Vervoort, J., and de Wit, P. J. 2006. Cladosporium fulvum Avr4 protects fungal cell walls against hydrolysis by plant chitinases accumulating during infection. Mol. Plant-Microbe Interact. 19:1420-1430.

van den Burg, H. A., Spronk, C. A., Boeren, S., Kennedy, M. A., Vissers, J. P., Vuister, G. W., de Wit, P. J., and Vervoort, J. 2004. Binding of the AVR4 elicitor of Cladosporium fulvum to chitotriose units is facilitated by positive allosteric protein-protein interactions: The chitin-binding site of AVR4 represents a novel binding site on the folding scaffold shared between the invertebrate and the plant chitin-binding domain. J. Biol. Chem. 279:16786-16796.

van den Burg, H. A., Westerink, N., Francoijs, K. J., Roth, R., Woestenenk, E., Boeren, S., de Wit, P. J., Joosten, M. H., and Vervoort, J. 2003. Natural disulfide bond-disrupted mutants of AVR4 of the tomato pathogen Cladosporium fulvum are sensitive to proteolysis, circumvent $C f$-4-mediated resistance, but retain their chitin binding ability. J. Biol. Chem. 278:27340-27346.

van den Hooven, H. W., van den Burg, H. A., Vossen, P., Boeren, S., de Wit, P. J., and Vervoort, J. 2001. Disulfide bond structure of the AVR9 elicitor of the fungal tomato pathogen Cladosporium fulvum: Evidence for a cystine knot. Biochemistry 40:3458-3466.

Van der Hoorn, R. A., Kruijt, M., Roth, R., Brandwagt, B. F., Joosten, M. H., and De Wit, P. J. 2001b. Intragenic recombination generated two distinct $C f$ genes that mediate AVR9 recognition in the natural population of Lycopersicon pimpinellifolium. Proc. Natl. Acad. Sci. U.S.A. 98:10493-10498.

Van der Hoorn, R. A., Roth, R., and De Wit, P. J. 2001a. Identification of distinct specificity determinants in resistance protein $\mathrm{Cf}-4$ allows construction of a Cf-9 mutant that confers recognition of avirulence protein Avr4. Plant Cell 13:273-285.

van Esse, H. P., Bolton, M. D., Stergiopoulos, I., de Wit, P. J., and Thomma, B. P. 2007. The chitin-binding Cladosporium fulvum effector protein Avr4 is a virulence factor. Mol. Plant-Microbe Interact. 20: 1092-1101.

van Esse, H. P., Van't Klooster, J. W., Bolton, M. D., Yadeta, K. A., van Baarlen, P., Boeren, S., Vervoort, J., de Wit, P. J., and Thomma, B. P. 2008. The Cladosporium fulvum virulence protein Avr2 inhibits host proteases required for basal defense. Plant Cell 20:1948-1963.

van Kan, J. A., van den Ackerveken, G. F., and de Wit, P. J. 1991. Cloning and characterization of cDNA of avirulence gene $a v r 9$ of the fungal pathogen Cladosporium fulvum, causal agent of tomato leaf mold. Mol. Plant-Microbe Interact. 4:52-59.
Vleeshouwers, V. G. A. A., and Oliver, R. P. 2014. Effectors as tools in disease resistance breeding against biotrophic, hemibiotrophic, and necrotrophic plant pathogens. Mol. Plant-Microbe Interact. 27:196-206.

Vleeshouwers, V. G. A. A., Rietman, H., Krenek, P., Champouret, N., Young, C., Oh, S.-K., Wang, M., Bouwmeester, K., Vosman, B., Visser, R. G. F., Jacobsen, E., Govers, F., Kamoun, S., and Van der Vossen, E. A. G. 2008. Effector genomics accelerates discovery and functional profiling of potato disease resistance and phytophthora infestans avirulence genes. PLoS One 3:e2875.

Webb, B., and Sali, A. 2002. Comparative protein structure modeling using MODELLER. Current Protocols in Bioinformatics. John Wiley \& Sons, Inc., Hoboken, NJ, U.S.A.

Wessels, J. 1994. Developmental regulation of fungal cell wall formation. Annu. Rev. Phytopathol. 32:413-437.

Westerink, N., Brandwagt, B. F., de Wit, P. J. G. M., and Joosten, M. H. A. J. 2004. Cladosporium fulvum circumvents the second functional resistance gene homologue at the $C f-4$ locus $(\mathrm{Hcr} 9-4 E)$ by secretion of a stable avr4E isoform. Mol. Microbiol. 54:533-545.

Whiteford, J. R., and Spanu, P. D. 2001. The hydrophobin HCf-1 of Cladosporium fulvum is required for efficient water-mediated dispersal of conidia. Fungal Genet. Biol. 32:159-168.

Wösten, H. A., van Wetter, M.-A., Lugones, L. G., van der Mei, H. C., Busscher, H. J., and Wessels, J. G. 1999. How a fungus escapes the water to grow into the air. Curr. Biol. 9:85-88.

$\mathrm{Wu}$, S., and Zhang, Y. 2008. MUSTER: Improving protein sequence profile-profile alignments by using multiple sources of structure information. Proteins 72:547-556.

Wulff, B. B., Heese, A., Tomlinson-Buhot, L., Jones, D. A., de la Peña, M., and Jones, J. D. 2009a. The major specificity-determining amino acids of the tomato Cf- 9 disease resistance protein are at hypervariable solventexposed positions in the central leucine-rich repeats. Mol. Plant-Microbe Interact. 22:1203-1213

Wulff, B. B., Thomas, C. M., Smoker, M., Grant, M., and Jones, J. D. 2001 Domain swapping and gene shuffling identify sequences required for induction of an Avr-dependent hypersensitive response by the tomato Cf- 4 and Cf-9 proteins. Plant Cell 13:255-272

Wulff, B. B. H., Chakrabarti, A., and Jones, D. A. 2009b. Recognitional specificity and evolution in the tomato-Cladosporium fulvum pathosystem. Mol. Plant-Microbe Interact. 22:1191-1202.

Xu, D., Jaroszewski, L., Li, Z., and Godzik, A. 2013. FFAS-3D: Improving fold recognition by including optimized structural features and template re-ranking. Bioinformatics 30:660-667.

Yang, Y., Faraggi, E., Zhao, H., and Zhou, Y. 2011. Improving protein fold recognition and template-based modeling by employing probabilisticbased matching between predicted one-dimensional structural properties of query and corresponding native properties of templates. Bioinformatics 27:2076-2082.

Zhang, Y. 2008. I-TASSER server for protein 3D structure prediction. BMC Bioinformatics 9:40.

\section{AUTHOR-RECOMMENDED INTERNET RESOURCES}

Big-PI Fungal Predictor server: http://mendel.imp.ac.at/gpi/fungi_server.html Clustal Omega server: https://www.ebi.ac.uk/Tools/msa/clustalo FFAS03/FFAS-3D server: http://ffas.sanfordburnham.org/ffas-cgi/cgi/ffas.pl FUGUE v2.0 server: http://mizuguchilab.org/fugue/prfsearch.html HHPred server: https://toolkit.tuebingen.mpg.de/tools/hhpred I-TASSER server: http://zhanglab.ccmb.med.umich.edu/I-TASSER JGI BLAST server:

http://genome.jgi.doe.gov/pages/blast-query.jsf?db=fungi MEME v4.11.2 server: http://meme-suite.org/tools/meme MUSTER server: http://zhanglab.ccmb.med.umich.edu/MUSTER NCBI BLAST server: https://blast.ncbi.nlm.nih.gov/Blast.cgi pGenTHREADER server: http://bioinf.cs.ucl.ac.uk/psipred/ Phyre2 server: http://www.sbg.bio.ic.ac.uk/phyre2/html/page.cgi?id=index RaptorX server: http://raptorx.uchicago.edu/StructurePrediction/predict RCSB protein databank: http://www.rcsb.org/pdb/home/home.do SignalP v3.0 server: http://www.cbs.dtu.dk/services/SignalP-3.0 SignalP v4.1 server: http://www.cbs.dtu.dk/services/SignalP SPARKS-X server: http://sparks-lab.org/yueyang/server/SPARKS-X TMHMM v2.0 server: http://www.cbs.dtu.dk/services/TMHMM 